\title{
A Study on the Correlation between Wood Moisture and the Damping Behaviour of the Tonewood Spruce
}

\author{
J. GÖKEN ${ }^{a}, *$ S. FAYED ${ }^{a}$, H. SCHÄFER ${ }^{a}$ AND J. ENZENAUER ${ }^{b}$ \\ ${ }^{a}$ University of Applied Sciences Emden-Leer, Faculty of Maritime Sciences, Bergmannstr. 36, 26789 Leer, Germany \\ ${ }^{b}$ Enzenauer Flügel-Manufaktur GmbH, Schulstr. 15, 51399 Burscheid, Germany
}

(Received September 8, 2017; in final form January 14, 2018)

\begin{abstract}
In acoustic musical instruments special attention needs to be paid to those particularly sensitive parts made of tonewood whose function is to respond to vibrations. One of the most important tonewoods is spruce because of its good resonance properties. Spruce is especially used for soundboards, these being the primary source of sound. Piano manufacturers dry their soundboards to approximately $6 \%$ wood moisture, at which drying stage they are glued into the instrument. Fluctuations of the moisture content in the wood affect the tone. With changing moisture content, the instrument can go out of tune, even cracks can appear at very low moisture content in the wood. In addition, the tone colour will change. This may result from changes in the hammer felt or from changes in the vibration properties of the soundboard. Strain- and frequency-dependent damping measurements were carried out on spruce wood at different wood moisture contents in order to investigate the effect of the moisture content on the vibration behaviour. Wood which is slowly dried in air for several years is preferably used for high-class pianos. Therefore, damping measurements on new and on more than 130-year old spruce wood samples were performed.
\end{abstract}

DOI: 10.12693/APhysPolA.133.1241

PACS/topics: spruce wood, musical instruments, wood moisture, damping measurement

\section{Introduction}

\subsection{Wood - a material \\ for the musical-instrument making}

Wood is an inhomogeneous, anisotropic, porous, and hygroscopic material of biological origin [1]. It is a natural construction material and has many advantages over other materials: high strength with good elasticity, high resistance against high load levels, corrosion resistance in saline water, good workability, low costs and, last but not least, its outstanding characteristic of environmental friendliness [2].

The strength of a flawless wood fibre is significantly higher than the strength of steel due to the favourable ratio of strength to the weight, Table I. The characteristic value is called breaking length. It describes how long a rod should be before breaking free by its own weight.

\begin{tabular}{c|c}
\multicolumn{2}{c}{ Breaking length of wood [3]. } \\
\hline \hline Material & TABLE I \\
\hline wood & 15000 \\
steel St37 & 4700
\end{tabular}

Consequently, and quite understandably, the fields where wood is used are widely diversified. It is, amongst other things, applied as a material for home building, furniture, musical instruments, truck and trailer flooring,

\footnotetext{
* corresponding author; e-mail: juergen.goeken@hs-emden-leer.de
}

rowboats, parts of snowboards, skis and skateboards, automobile chassis, ship masts and yardarms, paper and fluff products. Also, products made from wood derived chemicals like cellulose acetate and cellulose nitrate are to be considered [4].

Many physical and mechanical properties of wood are correlated with density. The Young's modulus, together with the wood's density, determine most of the acoustical properties of a material as shown by Wegst [5]. The most important acoustical properties for selecting materials for musical instruments are: the speed of sound within the material, the characteristic impedance, the sound radiation coefficient, and the dissipation of vibrational energy (material damping). Parameters like time, temperature and moisture content affect the mechanical properties of wood, therefore it is considered to be viscoelastic [6].

The most important tonewood in the manufacture of musical instruments is spruce, which is the preferred construction material for upright and grand pianos, bowed instruments (violin, viola, cello, double bass) and plucked instruments (guitar, harp, zither). Especially, wooden soundboards, being particularly sensitive to vibrations, are able to react to the vibration pattern of the piano strings and radiate the sound with all of its subtle distinctions. A classification diagram of traditional woods for string instruments and other instruments is shown by Yoshikawa and Waltham [7].

For a preliminary selection of spruce timber, a number of factors play a role: the region and the altitude of growth, the mineral composition of the soil, the direction of the sloping site, the type of spruce and the time of felling. In earlier days, the tones of pre-selected spruce tree trunks were evaluated after strucking them with wooden rods in the forest. Consequently, the trees 
were felled, the logs were transported and cut at the sawmill. That was followed by a process of slow drying — preferably in the open air — for several years. Wood defects like knots, cracks and resin pockets can lead to unwanted noises in the finished instrument (buzzing, rattling) and should be avoided. Further sound quality improvement factors are the number of annual growth rings per centimetre and the position of the annual rings relative to each other.

From the musical-instrument maker's point of view, especially from that of violin makers, guitar builders, and piano makers, it can be stated that the resonance behaviour of old spruce wood entails a more harmonic sound characterised by a clearer and warmer tone which can be attributed to an age-related change of the Young's modulus. The sound is also marked by a higher volume and a fast response of the tone.

In own preliminary studies, acoustic experiments on a double bass were performed in order to demonstrate the change of the sound distribution on the top plate after a slight alteration of the mechanical load on the bridge, Fig. 1. The sound distribution was determined by measuring the local sound pressure level using a sound source localisation system. The area with the highest vibration activity was colour-coded in red, that with lower vibration activity in blue. Other colours represented intermediate values. The comparison between Fig. 1a and Fig. 1b shows that already a slight alteration of the external mechanical load can lead to significant changes of the sound distribution. This illustrates the problem with regard to vibration analysis of musical instruments.

The situation is compounded by the fact that even the vibration analysis of an oscillating plate is difficult. Exact mathematical solutions of the differential equation for a vibrating plate are extremely rare because the individual boundary conditions have to be met. For that reason, former work was targeted on the visualisation of the vibration behaviour of a clamped square plate using a sensitive sound localisation system which measured the local particle velocity of an oscillating acrylic glass pane. Further details can be found in the work of Göken et al. [8]. The comparison with the sand figures representing the Chladni figures showed that the highest particle velocity occurred in the center of the pane where hammering of a lifting magnet took place. The excitation frequency was $20 \mathrm{~Hz}$, Fig. 2.

Firstly, the edges of the pane were clamped homogeneously (Fig. 2a). When four bar clamps were removed (Fig. 2b, red marks), the vibration pattern was not anymore as dendritic as before. The demounting of some bar clamps appeared to be sufficient to change the vibrating structure significantly.

The results of the acoustic measurements clearly suggest that a musical instrument like a piano represents a complex construction. Due to the mounting of different parts with individual vibration behaviours, a prediction of the overall sound experience is almost impossible. Therefore, measurements on individual parts and their
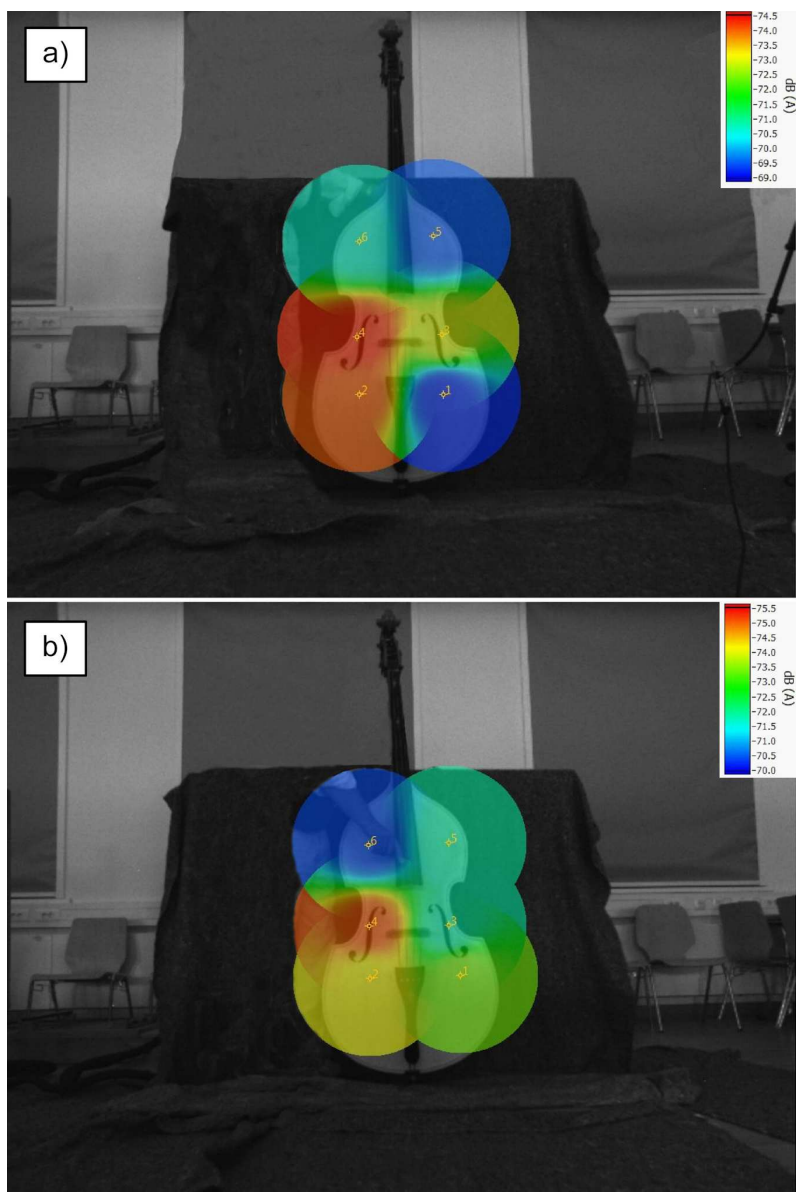

Fig. 1. Sound distribution on the top plate of a double bass, (a) before and (b) after controlled change of the mechanical stress on the bridge. In order to focus exclusively on the musical instrument, the playing musician was retouched.

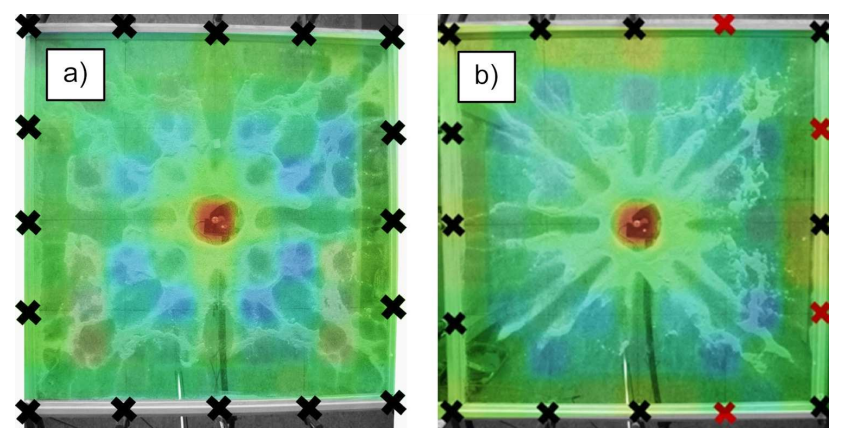

Fig. 2. (a) Vibration pattern of a square acrylic glass pane fixed at 16 positions (marked as X); central excitation, excitation frequency $20 \mathrm{~Hz}$; (b) vibration pattern of the same square acrylic glass pane after releasing the fixation at 4 positions (marked as $\mathrm{X}$ ).

mechanical properties are the driving forces for the optimisation of the acoustic design. These properties must be properly considered in order to make at least a rough estimation of the sound characteristics. The sound characteristics itself is strongly dependent on the moisture status of the wood which has to be investigated precisely. 
Piano manufacturers dry their soundboards to approximately $6 \%$ wood moisture, at which drying stage they are glued into the instrument. This procedure makes the soundboard more resistant to the development of drying cracks which can be formed as a result of a reduction in the relative humidity in heated rooms during the winter season. Later, these instruments are usually placed in heated and permanently closed rooms (inside rooms, living rooms, concert halls). At room temperature, a wood moisture of $9 \% \pm 3 \%$ can occur in such rooms as a result of moisture balancing between the wood and the atmosphere.

\subsection{Wood structure}

In order to understand the moisture state in wood, it is necessary to concentrate on the wood structure. The wood structure consists of wood cells with various sizes and shapes. Dry wood cells are either empty or partly filled with deposits, such as gums and resins, or with tyloses [9]. In spruce wood, the cells are elongated fibres (tracheids) containing a cell cavity (lumen) therein. The water absorption occurs mainly in the lumens, and restrictedly in the wood fibres.

The cell wall of a tracheid is composed of a middle lamella (ML), a primary wall (P) and a compound secondary wall $(\mathrm{S})$, which are laid down sequentially as the cell is formed. The middle lamella contains an intercellular material that cements neighbouring cells together. Three distinct layers that differ in their microfibril orientation are identified in the secondary cell wall; these are referred to as the $S_{1}, S_{2}$ and $S_{3}$ layers [10], Fig. 3 .

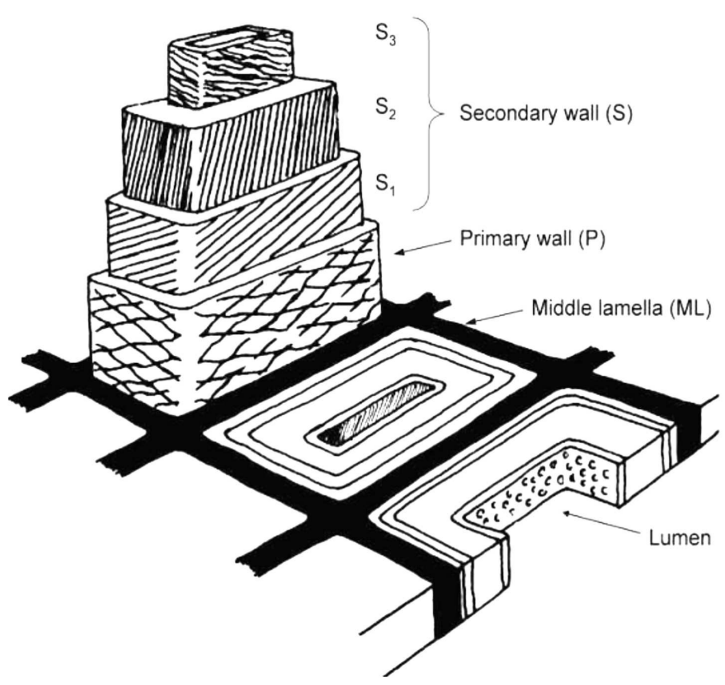

Fig. 3. Schematic representation of the structure of the cell wall of a Sitka spruce tracheid (taken from Ref. [10]; after Eaton and Hale [11]).

Water in wood takes two forms - free water and bound water. Free water exists as liquid and vapour in cell cavities (lumens). Free water is not chemically associated and therefore does not influence mechanical properties. Bound water exists in the cell wall and is as- sociated with the cell wall polymers through hydrogen bonding with accessible hydroxyl $(-\mathrm{OH})$ groups on the cell wall biopolymers (amorphous cellulose, hemicelluloses and lignin) [12]. Cellulose is characterised by long chains of glucose which is produced by photosynthesis. Cellulose molecules combine to form elementary fibres, which are in turn grouped into bundles called microfibrils which, on the one hand, are forming the major structural component in cell walls and, on the other hand, play an important role in the wood-moisture relationship [13]. Water binds with the cellulose fibres (microfibrils) in the cell wall. Hemicellulose is an another component of the wood's secondary cell wall and usually embedded among cellulose microfibril bundles [14].

The question, if the particular sound behaviour of the wood of, for example, a Stradivarius violin is caused by the additional injection of chemical substances or by agerelated chemical transformations inside the wood is still unanswered and, therefore, subject of scientific studies carried out on old musical instruments, e.g. Ref. [15]. The influence of chemical additives to change the acoustic behaviour of wood is an important area of investigation as shown by Yano et al. [16]. They analysed the effects of three chemical treatments (a low molecular weight phenolic resin treatment, a resorcin/formaldehyde treatment, and a saligenin/formaldehyde treatment) on the acoustic properties of Sitka spruce wood. Tai et al. [17] carried out a quantitative assessment of wood chemical changes in antique musical instruments, using a combination of the analytical methods NMR, synchrotron X-ray, differential scanning calorimetry (DSC), thermal gravimetric analysis (TGA), and inductively coupled plasma - mass spectrometry (ICP-MS). The chemical changes associated with dry aging were hemicellulose decomposition, lignin oxidation, and reduced equilibrium moisture content.

Wood absorbs water in two different procedures. Firstly, the cell walls accumulate. If these are saturated, the cell cavities are filled [3]. The moisture content of water in wood depends particularly on two factors: ambient temperature and humidity.

As wet wood dries, free water leaves the lumens first. After all of the free water has disappeared and only bound water remains, the cell reaches its fibre saturation point (fsp). At this point, no water is present in the cell lumen, but the cell wall is completely saturated with water between the microfibrils [13]. Conifers attain this condition at about $30 \%$ wood moisture [18].

Diffusion is the water transport mechanism in wood. It takes place as either bound water diffusion $D_{b}$ or water vapour diffusion $D_{v}$ or a combination of the two, see Fig. 4.

Intertracheid bordered pit pairs contribute to the water transport from one fibre to another. These pit pairs are circular openings in adjacent cell walls, spanned by a thin membrane which is a continuation of the compound middle lamella [20]. Most of these pit pairs are located on the radial surface of the fibres, Fig. 5. 


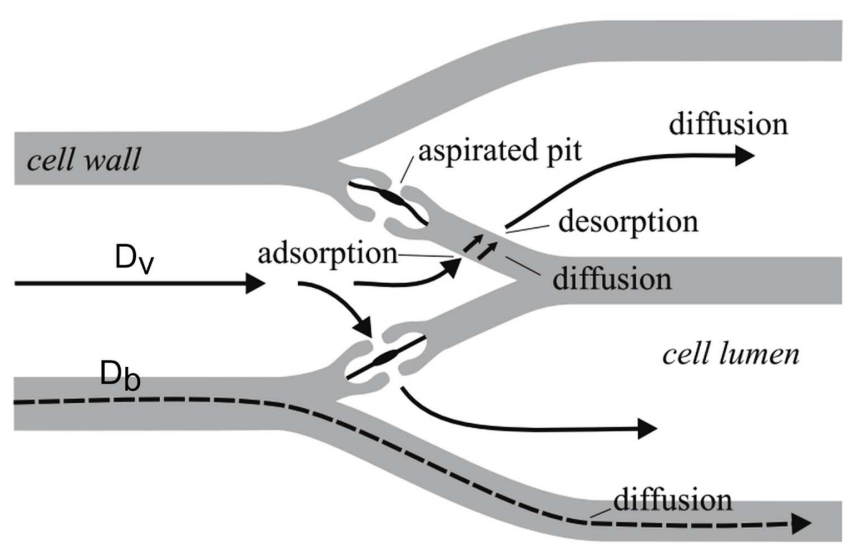

Fig. 4. Different paths of moisture transport through wood. $D_{v}(-)$ is the vapour diffusion and $D_{b}(--)$ is the bound water diffusion; after Ref. [19].
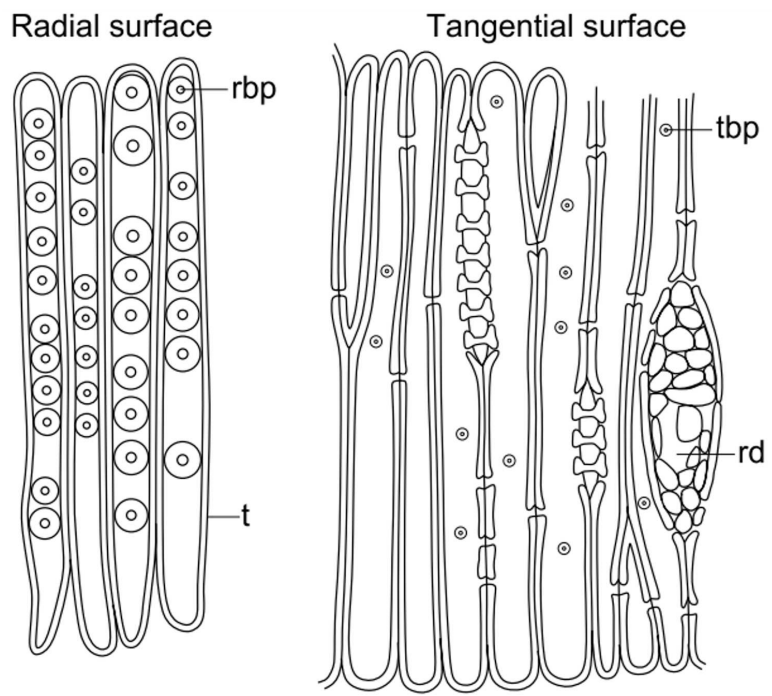

Fig. 5. Radial and tangential surfaces of fibres (tracheids). The size and the amounts of bordered pits can be seen. $(\mathrm{t}=$ tracheid, $\mathrm{rbp}=$ radial bordered pit, tbp $=$ tangential bordered pit, $\mathrm{rd}=$ resin duct); taken from Ref. [20].

The knowledge of the moisture content of tonewood in musical instruments is very important because fluctuations of the moisture content in the wood affect the tone. For one thing, the instrument could go out of tune and at very low moisture content, cracks can appear in the wood. In addition, the tone colour will change. This may result from changes in the hammer felt or from changes in the vibration properties of the soundboard. Therefore, the wood moisture content and its impact on the vibration properties in terms of the material damping are necessary to be investigated.

\subsection{Vibration damping}

Manufacturers of high-quality grand pianos and pianos attach particular importance to the use of tonewood with low damping. From the practical point of view, the fol- lowing wood properties could be regarded as good indicators for low damping: narrow annual rings, standing years, slow growth of the tree, and thus high hardness of the late wood zones.

Essentially, three sources of damping in wood are available: (i) the damping of the wood itself, (ii) the slip damping at surfaces in contact at joints and connections, and (iii) the damping provided by special adhesive layers in glued construction [21].

For an applied stress due to an external force varying sinusoidally with time, a viscoelastic material like wood will consequently respond with a corresponding sinusoidal strain for low amplitudes of stress. The sinusoidal variation in time is usually described as a rate specified by the excitation frequency $\omega$ ( $\omega=$ angular frequency). The strain $\varepsilon$ of a viscoelastic body is out of phase with the applied stress $\sigma$, leading to the phase angle $\delta$, Fig. 6. This phase lag is due to the excess time, which is necessary for atomic or molecular motions and relaxations to occur [23].

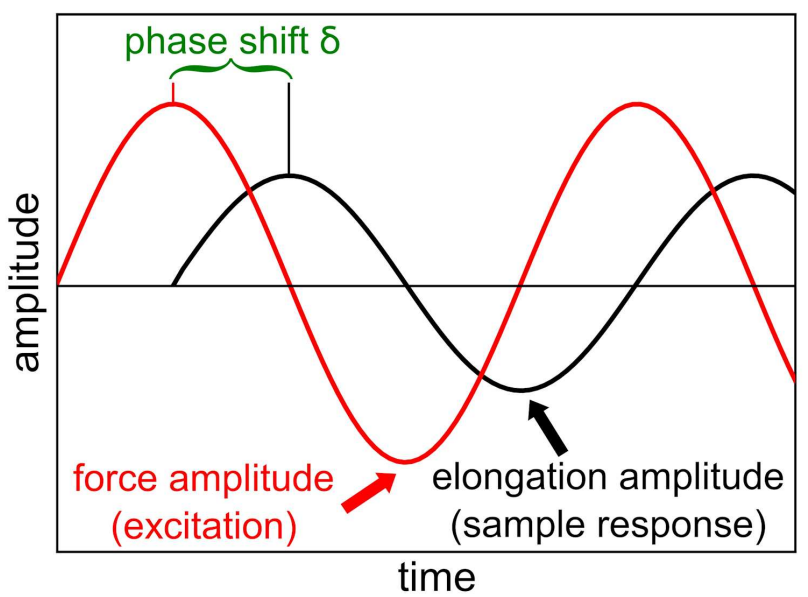

Fig. 6. Sinusoidal oscillation of the exciting force and sample response of a viscoelastic material.

At a dynamic load, $\sigma$ and $\varepsilon$ are given in the comfortable complex notation as

$$
\begin{aligned}
& \sigma=\sigma_{0} \mathrm{e}^{\mathrm{i} \omega t}=\sigma_{0}(\cos (\omega t)+\mathrm{i} \sin (\omega t)), \\
& \varepsilon=\varepsilon_{0} \mathrm{e}^{\mathrm{i}(\omega t-\delta)},
\end{aligned}
$$

where $\sigma_{0}$ is the stress amplitude, $\varepsilon_{0}$ is the strain amplitude and $\mathrm{i}$ the imaginary unit with $\mathrm{i}^{2}=-1$.

From Eq. (1) and (2) a complex modulus of elasticity $E^{*}$ (so-called dynamic modulus) can be obtained consisting of a real and imaginary part as

$E^{*}=\frac{\sigma}{\varepsilon}=\frac{\sigma_{0}}{\varepsilon_{0}} \mathrm{e}^{\mathrm{i} \delta}=\frac{\sigma_{0}}{\varepsilon_{0}}(\cos \delta+i \sin \delta)=E^{\prime}+\mathrm{i} E^{\prime \prime}$,

i.e. $E^{\prime}=\left|E^{*}\right| \cos \delta$ and $E^{\prime \prime}=\left|E^{*}\right| \sin \delta$.

The real (storage) part $E^{\prime}$ describes the ability of the materialto store potential energy and release it upon de- 
formation. The imaginary (loss) portion $E^{\prime \prime}$ is associated with energy dissipation in the form of heat upon deformation. The loss factor $\tan \delta$ is the ratio of the loss modulus to the storage modulus. It is a measure of the energy loss, expressed in terms of the recoverable energy, and represents mechanical damping or internal friction in a viscoelastic system. Using $E^{\prime}$ and $E^{\prime \prime}$ from Eq. (3) the material damping can be received as

$$
\tan \delta=\frac{E^{\prime \prime}}{E^{\prime}} .
$$

Figure 7 shows the dependence of the loss factor $\tan \delta$ on $E^{\prime}$ and $E^{\prime \prime}$ which are the real and the imaginary component of the complex modulus $E^{*}$, respectively. In case of the dominance of the elastic behaviour of the material, the storage modulus $E^{\prime}$ is larger than the loss modulus $E^{\prime \prime}$ which leads to a small loss factor. If $E^{\prime \prime}$ increases, the viscous behaviour of the material is significant.

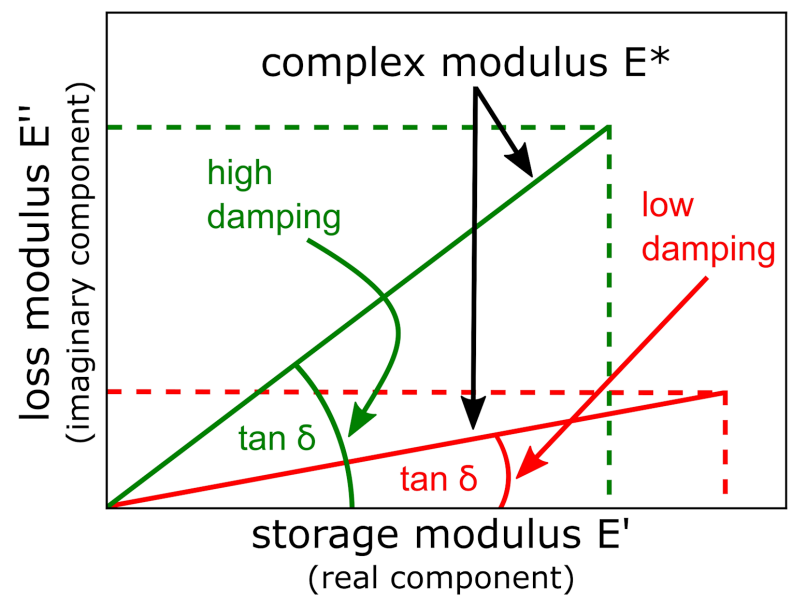

Fig. 7. Determination of the loss factor $\tan \delta$ from the storage modulus $E^{\prime}$ and the loss modulus $E^{\prime \prime}$.

According to Ashby [24] the value of the material damping (in terms of $\tan \delta$, at $30^{\circ} \mathrm{C}$ ) of wood is expected to be in the region between 0.1 and 0.01 . Taking the classification by Golovin [25] into account, low damping materials have a value of $\tan \delta$ below 0.1 , whereas that value for high damping is considered to be above 1. Therefore, wood can be considered as a low damping material. Referring to Eq. (4) it is obvious that $\tan \delta$ and $E^{\prime}$ are reciprocal to each other. For low damping materials, the storage modulus $E^{\prime}$ (measure of elastic response) becomes dominant and is very similar to the Young's modulus $E$.

Soundboards are made from low density woods, which have a relatively high Young's modulus [5] and, consequently, a low loss factor $\tan \delta$. This conclusion is supported by a former work of Ono and Norimoto who reported that wood having higher Young's modulus $(E)$ per specific gravity $\gamma$ and lower internal friction $Q^{-1}$ (with $Q^{-1} \approx \tan \delta$ ) is suitable for soundboards of musical instruments [26]. Spruce wood is a low density wood with relatively high Young's modulus. Optimised acoustic properties can be expected from spruce wood which comes preferably from heights above $800 \mathrm{~m}$, cool growth regions (north slopes) and locations with mineralcontaining soil.

\section{Experimental}

In this work, spruce wood of two different ages (new and about 130 years old) were investigated. The old wood samples were taken from a discarded ancient piano. The samples needed for the conducted experiments were machined to rectangular shaped rods (specimen size: $80 \mathrm{~mm}$ length, $10 \mathrm{~mm}$ width and $3 \mathrm{~mm}$ thickness; the thickness was reduced to $1 \mathrm{~mm}$ when damping measurements were performed). The precise machining led to an almost equal front surface of the samples (maximum error of the front surface was less than 11\%).

Knowing if the inner annual ring structure is standing (vertical) or lying (horizontal) provides information about how resistant the wood is to rot and cracks and how the wood can be used [27]. By definition annual rings are vertical when the angle between the flat side of the sawn wood and a tangent to the annual ring in the surface of the wood is between 60 and 90 degrees [28]. In Fig. 8 the deformation of wood cross-sections as a result of shrinkage is illustrated. In order to obtain high dimensional stability (small shrinkage) and isotropic movements with changing humidity conditions, the samples used in this work were taken from a position with standing annual growth rings in the front surface of the rectangular specimens, Fig. 9.

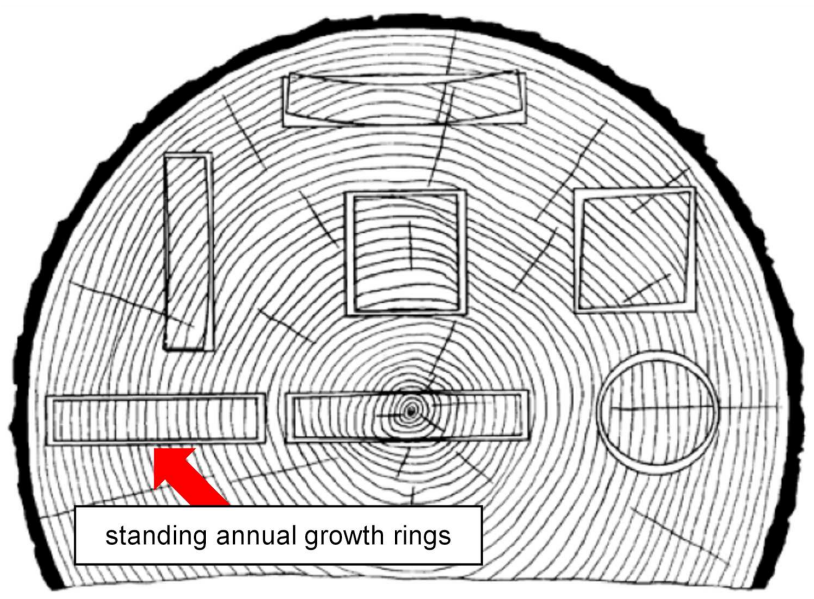

Fig. 8. Characteristic shrinkage and distortion of flat, square, and round pieces as affected by direction of growth rings. Tangential shrinkage is about twice as great as radial; after Ref. [29].

The equilibrium moisture content (EMC) of water is defined as that moisture content (MC) at which the wood is neither gaining nor losing moisture. This value changes with the humidity surrounding it [29]. The equilibrium moisture content of wood during drying (desorption) is higher in the same relative humidity than when 

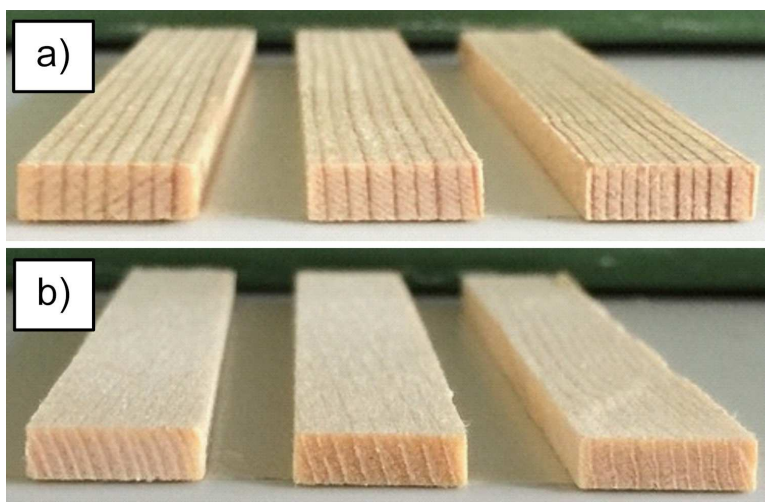

Fig. 9. (a) Old and (b) new spruce wood with standing annual growth rings.

the wood's moisture content increases (adsorption) [30]. Such a difference in moisture adsorption and desorption leads to a hysteresis as shown in Fig. 10. According to Derome et al. [31] the hysteresis of water sorption, in the hygroscopic range of wood, is related to a smaller number of available hydroxyl sites to adsorb water molecules in adsorption than in desorption.

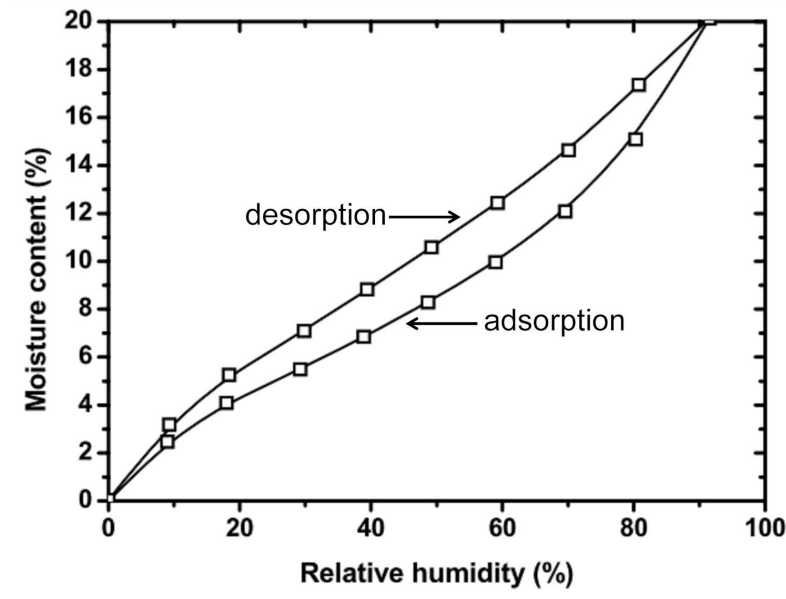

Fig. 10. Moisture adsorption and desorption behaviour for the Sitka spruce wood; after Ref. [32].

In this work, special focus was placed on the drying (desorption) of wood. The concentration on the wood drying is important in instrument making because of some fundamental reasons provided by Reeb [33]:

1. Better usability. (Wood shrinks as it loses moisture and swells as it gains moisture. It should be dried to the percentage value of the moisture content it will have during use.)

2. There is less likelihood of stain or decay during transit, storage, and use.

3. Reduced susceptibility to insect damage.

4. Increased strength because as wood dries below $30 \%$ moisture content, most strength properties increase.
5. Nails, screws, and glue hold better in seasoned wood.

The BDK e.V. (association of German piano makers) recommends a relative humidity of 50 to $60 \%$ for pianos used in an interior location [34]. Another German association (Bundesverband Klavier e.V.) indicates a relative humidity of 40 to $65 \%$ as an ideal application range of pianos [35]. With the help of climate control devices for pianos the relative humidity in the immediate surroundings of the piano is adjustable, at least the natural fluctuations of the relative humidity can be counteracted.

All measurements (see following subsections) in this work were performed at ambient temperature and a relative air humidity of about $58 \%$. This measured value was in accordance with calculated literature data [29] considering the relationship between equilibrium moisture content (EMC), relative humidity and temperature.

\subsection{Microscopic investigations and determination of moisture content}

For later damping measurements, which were carried out in correlation with a decreasing moisture content of both woods, it was necessary to investigate both the asreceived state of each sample and the development of the water distribution inside the structure. A microscopic analysis was carried out using a digital microscope (Di-Li 1027-HD, Distelkamp-Electronic, Kaiserslautern, Germany), Distelkamp-Electronic, Kaiserslautern, Germany). The applied transmitted light mode made it necessary to reduce the wood thickness of samples for microscopic analysis. One half of the $3 \mathrm{~mm}$ thick specimen was sanded to a thickness of about $0.6 \mathrm{~mm}$. A small hollow was drilled in the thicker half of the wood sample, into which ink-mixed water was dripped.

The ink-mixed water was used for a more definable representation of the water motion in wood during the microscopic analysis. By dripping the coloured water into the hollow, it could be ensured that the fluid is able to moisten the wood steadily.

Pictures were continuously recorded (utilising software Grab \& Measure, A-ZYSTEMS, Mainz, Germany) with an interval of $30 \mathrm{~s}$ over a period of one hour, where the drying process of the specimen could be specifically observed. The samples were investigated by a total magnification of $2000 \times$ (optical magnification of $200 \times$ and digital magnification of $10 \times)$.

The recorded pictures could be then analysed with the help of a self-written LabVIEW (National Instruments ${ }^{\top M}$ ) code. The microscope's RGB images are normally stored as an m-by-n-by-3 data array, where each dimension defines the Red, Green and Blue colour components for each individual pixel. The code read around 620 RGB images subsequently and converted them into grey-scaled ones by averaging each of the R, G and B-values to get one average number that ranged from 0 (black) to 255 (white) representing the brightness of the pixel. Assuming that the value of $100 \%$ illustrates an intensity of 255 , 
the percentage of the colour intensity for each pixel in each image could be calculated. For a better representation of the percent content of ink-mixed water (dark colour) in a specimen, each of the intensity values (in \%) was subtracted from a value of $100 \%$. In Fig. 11 the greyscaled micrographs of old (Fig. 11a) and new spruce wood (Fig. 11b) are shown. These images were taken for the calculation of the percent change of darkness (resulting from injecting the specimens with an ink-mixed water) over time.
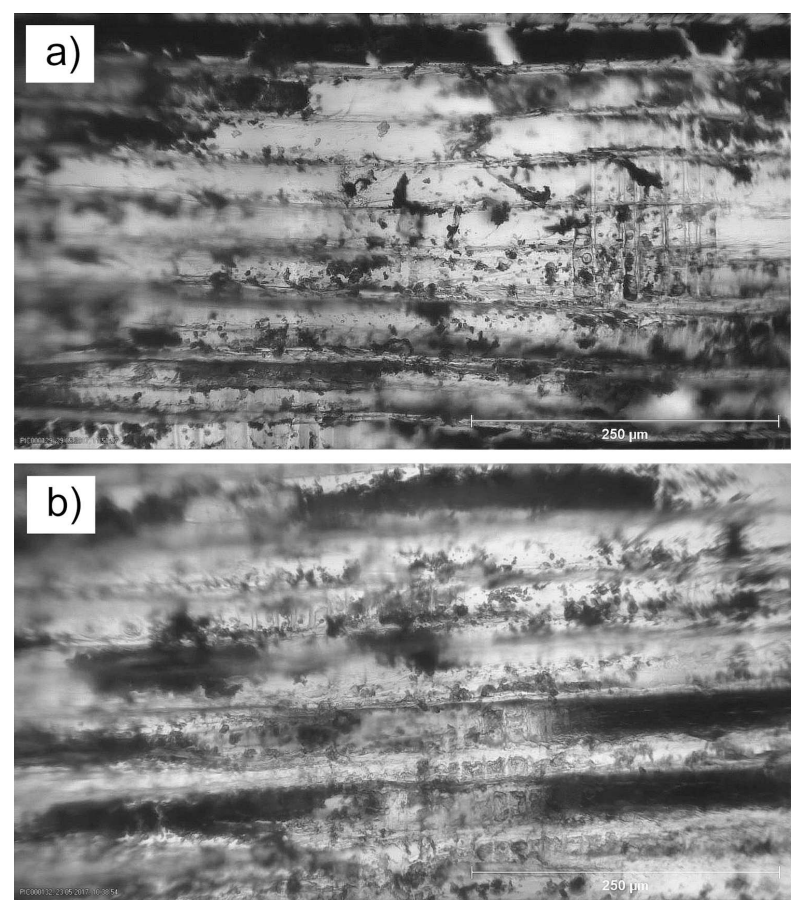

Fig. 11. Grey-scaled microscopic image of (a) old wood and (b) new spruce wood.

Focusing on the desorption, the time-dependent decrease of the moisture content of old and new spruce wood was measured by a pin-type wood moisture meter (Voltcraft ${ }^{\circledR}$ FM-300), with the help of measuring the electrical resistance between two plug gauges. These gauges were inserted into the piece of wood whereas in the moisture range from $8 \%$ to about $40 \%$ at least an accuracy of $\pm 1 \%$ was available. Two similar samples were placed on a grid, which was put on a pot of boiling water. Each sample was subjected over an hour to water vapour to reach a moisture value of around $45 \%$. One sample was used for later damping measurements while the other acted as a reference specimen for the determination of the current moisture content. The reference sample was left to dry in the air at room temperature, while its decreasing moisture content was continuously measured at $30 \mathrm{~s}$ intervals.

The error in the moisture content change ( $\mathrm{MC}$ in \%) had been primarily determined in initial experiments by subjecting three old and three new spruce wood specimens of the same dimensions to water vapour using the above mentioned process. The mean value of the relative standard deviation of four measured moisture content values (at 900,6360, 18240, and at $34140 \mathrm{~s}$ ) at each of the 6 samples was $8.2 \%$ in case of old wood, and $7.3 \%$ in case of new wood. Therefore, a rough estimation of the moisture content error of about $10 \%$ in the time range from $0 \mathrm{~s}$ up to nearly $35000 \mathrm{~s}$ for both sample types could be made.

\subsection{Damping equipment}

\subsubsection{Experimental setup}

Damping was measured with the help of a dynamic mechanical analyser (DMA). Dynamic mechanical analysis is a technique used to study and characterise materials with respect to material phase transitions and the response to mechanical and thermal stress. This is particularly applicable for viscoelastic materials.

DMA machines work under the concept of applying a force to a material and analysing the material's response to that force (a non-resonance method). The force used in this case is sinusoidal and oscillates at a range of frequencies, typically $0.01-100 \mathrm{~Hz}$, and across a range of temperatures, typically $-150{ }^{\circ} \mathrm{C}-500^{\circ} \mathrm{C}$. From analysing this response, the DMA software is able to calculate various parameters from the recorded dynamic modulus $E^{*}[36,37]$.

Figure 12 shows the schematic construction of the dynamic mechanical analyser whose specification is listed in Table II.

TABLE II

Specification EPLEXOR ${ }^{\circledR} 500 \mathrm{~N}$ [38].

\begin{tabular}{c|c|c|c|c|c}
\hline \hline $\begin{array}{c}\text { Total } \\
\text { force }\end{array}$ & $\begin{array}{c}\text { Dynamic } \\
\text { force } \\
\text { amplitude }\end{array}$ & $\begin{array}{c}\text { Total } \\
\text { deformation }\end{array}$ & $\begin{array}{c}\text { Dynamic } \\
\text { strain } \\
\text { amplitude }\end{array}$ & $\begin{array}{c}\text { Range of } \\
\text { frequency }\end{array}$ & $\begin{array}{c}\text { Range of } \\
\text { temp. }\end{array}$ \\
\hline $1500 \mathrm{~N}$ & $\pm 500 \mathrm{~N}$ & $30 \mathrm{~mm}$ & $\pm 3 \mathrm{~mm}$ & $\begin{array}{c}0.01 \mathrm{~Hz} \\
\text { to } 100 \mathrm{~Hz}\end{array}$ & $\begin{array}{c}-150^{\circ} \mathrm{C} \\
\text { to } 500^{\circ} \mathrm{C}\end{array}$
\end{tabular}

The samples were fixed at both ends as well as in the middle, and statically and dynamically loaded in the middle using a dual cantilever holder. The static load was set to $1 \mathrm{~N}$ and was realised by a servo motor. The dynamic load is based on the chosen material's strain range which has to be covered. The material strain $\varepsilon$ is obtained from $\varepsilon=\frac{\Delta h}{h}$ where $h$ is the thickness and $\Delta h$ is the maximum deflection of the sample. $\varepsilon$ is denoted here as deflection strain.

Strain-dependent damping measurements at constant frequencies $(12,22,33,35,75 \mathrm{~Hz})$ were carried out at a range of the dynamic load ranging from $0.3 \%$ of $h$ to $50 \%$ of $h$ whereas the dynamic force was generated by an electrodynamic shaker system. An incremental rise of the dynamic force of $1.99 \%$ of $h$ was applied.

Prior to the actual measurements, the error in the strain-dependent measurements on three old and three new spruce wood samples had been determined. The used samples for the statistics had the same dimensions and a moisture content of $15 \% \pm 1 \% \mathrm{MC}$ in case of old 


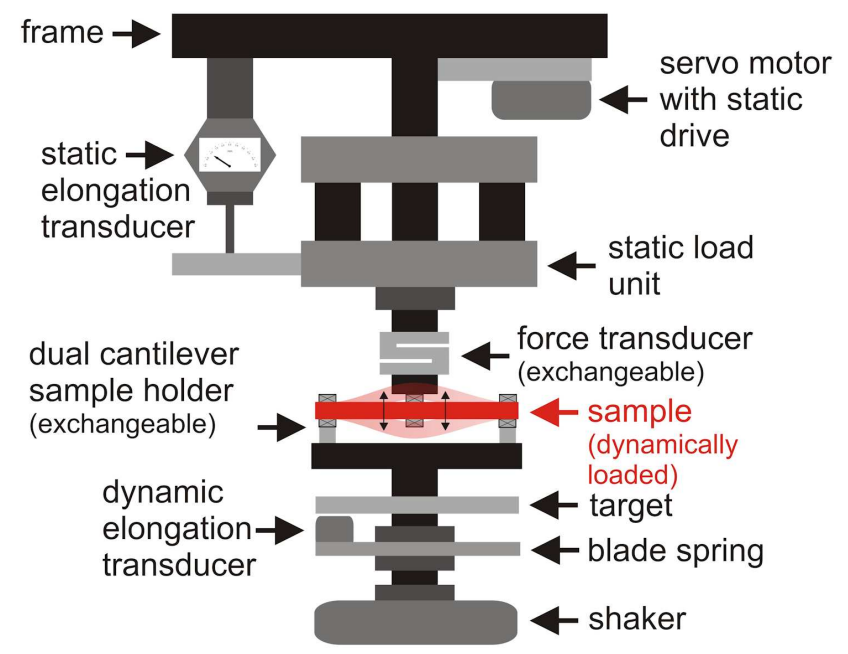

Fig. 12. Schematic layout of the dynamic mechanical analyser (DMA, EPLEXOR ${ }^{\circledR} 500 \mathrm{~N}$; based on Ref. [38]).

and in case of new wood. 26 damping values (in terms of $\tan \delta$ ) at a strain range of 0.3 to $50 \%$ were measured for each of the 6 samples. The mean value of the relative standard deviation was $6.2 \%$ in case of old wood and $3.3 \%$ in case of new wood. These error values of the strain-dependent measurements correlate with corresponding data in the literature [39] which indicate an error of less than $10 \%$ for an individual strain-dependent damping measurement of spruce wood.

Additionally, frequency-dependent damping measurements ranging from $0.3 \mathrm{~Hz}$ to about $70 \mathrm{~Hz}$ (increment: $11.39 \mathrm{~Hz}$ ) at a dynamic load of $50 \%$ of $h$ were performed. In instrument making, particular attention has to be paid to low frequencies: they are less damped and, therefore, are always present in conjunction with their associated partial tones. Low frequencies sound longer and form larger vibrational islands. These islands are easier to manipulate, with the goal that the sound of the vibrational islands can be better adapted to the tonal overall picture. The lowest frequency on a piano keyboard is $27.5 \mathrm{~Hz}$. A clear influence on the sound can be perceived up to five times the basic tone. Accordingly, the partial tones must be considered in the sound optimisation even at frequencies around $5 \mathrm{~Hz}$. For these reasons, the choice of the mentioned (low) frequency range had been reasonable for the applied experiments.

For the purpose of assurance of accuracy of the results, preliminary tests of frequency-dependent damping measurements (following the experimental conditions described above) had been applied on three old and on three new spruce wood samples, each at a moisture content of $10 \% \pm 1 \%$. Eight damping values (represented as $\tan \delta$, increment: $11.39 \mathrm{~Hz}$ ) at a frequency range from $0.3 \mathrm{~Hz}$ to $70 \mathrm{~Hz}$ were measured for each of the six samples. The mean value of the relative standard deviation was $7.4 \%$ in case of old wood and $3.9 \%$ in case of new wood.

\section{Results and discussion}

\subsection{General results of the structure and the moisture observation}

Figure 13 shows microscope images of old (Fig. 13a) and new (Fig. 13b) wood in as-received condition (moisture content $\approx 8 \%$ ). Both samples of different ages show elongated tracheids with pits for the water transport from one tracheid to another as schematically illustrated in Fig. 5. In case of old wood, the structural framework could be more definably observed than that of the new sample. This could be referred to naturally degraded cell components which are still present in the new wood. Due to this fact, the performance of transmitted light microscopy was more difficult even when the thickness of the new sample had been reduced compared to the old wood specimen.
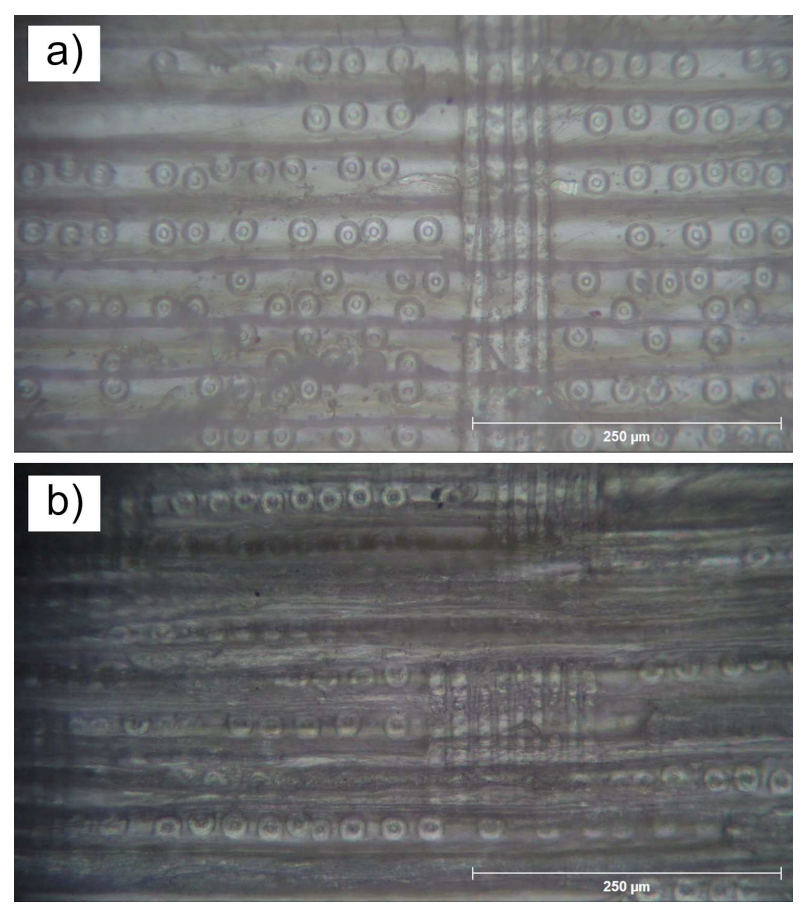

Fig. 13. Horizontally and vertically running fibres (tracheids) with pits (serving as a recess for the exchange of material) of (a) old wood and (b) new wood; microscopic image $(2000 \times$ magnification, digital transmitted light microscopy).

Because of the decisive impact of moisture on the tone of wood used for musical instruments, the moisture content or moisture distribution in the old and new wood is of major interest. In Fig. 14, the rate of moisture loss in terms of the rate of darkness change after introducing the ink-mixed water into the old spruce wood as function of the time is illustrated. The initial moisture content for old spruce wood was about $42 \%$, that of new wood about $43 \%$. After a time of approximately $3500 \mathrm{~s}$, a final moisture content of nearly $11 \%$ for both samples was obtained. 


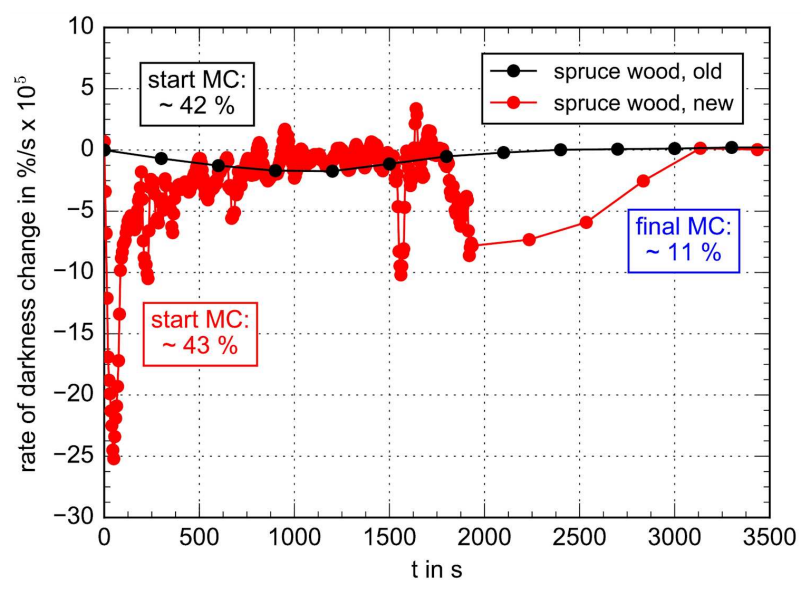

Fig. 14. Microscopic analysis of the darkness change after introducing the ink-mixed water into old and new spruce wood.

It is obvious that the velocity of moisture release for the specimen of old spruce wood is more or less constant in contrast to the corresponding behaviour of the new sample. In the beginning of the red curve (time interval from $0 \mathrm{~s}$ to nearly $100 \mathrm{~s}$ ) the darkness change is increasing and can be explained by a rapid loss of moisture. Drying occurs firstly in the cell lumens (acting as storage facility) containing the free water.

After that, a slowdown of moisture release takes place which may be referred to the beginning of the loss of bound water. The increase in the darkness change in the range of about $1500 \mathrm{~s}$ to $2000 \mathrm{~s}$ is assumed to be an incipient transfer of water to other lumens or even into the cell walls ( $\rightarrow$ distribution of water by diffusion). It is therefore expected that a larger proportion of water now exists between the microfibrils as bound water.

In case of new wood there is no continuous slowdown of moisture release to the equilibrium moisture content $(\approx 11 \% \mathrm{MC})$ which is established for larger time values of about $3000 \mathrm{~s}$ (see Fig. 14). Instead, it seems that the moisture loss is interrupted by "intermediate stages" which have to be overcome. Consequently, this explains why it is necessary in instrument making to dry freshly cut wood for a long time.

Such an intermediate stage is in accordance with results of Sakai et al. [40] who investigated the effect of moisture content on the attenuation in woods. They assumed an intermediate region of quasi-equilibrium, where the free water begins to leave the cell space but yet the cell walls are still saturated with the absorbed water. Based on that assumption, we interpret the observed changing rate of moisture release behaviour as a dynamic interplay of water flow from the cell wall into the lumens and back again. Although the amount of free water in this intermediate region is expected to be generally very small, it is supposed that it has a substantial effect on the material damping.

It should be underlined that moisture changes in response to daily humidity changes are small but could have a significant influence on the brightness of a musical tone. In the case of well-preserved grand pianos from the period before the Second World War, in particular if they are original or are still very close to the original condition, pianists repeatedly note that the tone colour may change from day to day due to changes of the climatic conditions. This is not or less noticeable for new grand pianos. Due to the high sensitivity to surrounding humidity conditions, particular attention has thus to be paid to the drying process of wood [41], especially of old wood but less of new wood. Experience in the instrument making has shown that old wood reacts more quickly to humidity changes than new wood. This fact is supported by the uniform drying process of old wood (Fig. 14).

In Fig. 15, the current moisture content is plotted versus the drying time $t$ for old and new spruce wood. Starting from an initial moisture content of about $47 \%$, both curves reach an EMC of nearly $11 \%$. It could be observed that the time needed for achieving that EMCpoint is different for each wood type (old spruce wood: $t_{\mathrm{EMC}} \approx 12500 \mathrm{~s}$, new spruce wood $\left.t_{\mathrm{EMC}} \approx 7500 \mathrm{~s}\right)$.

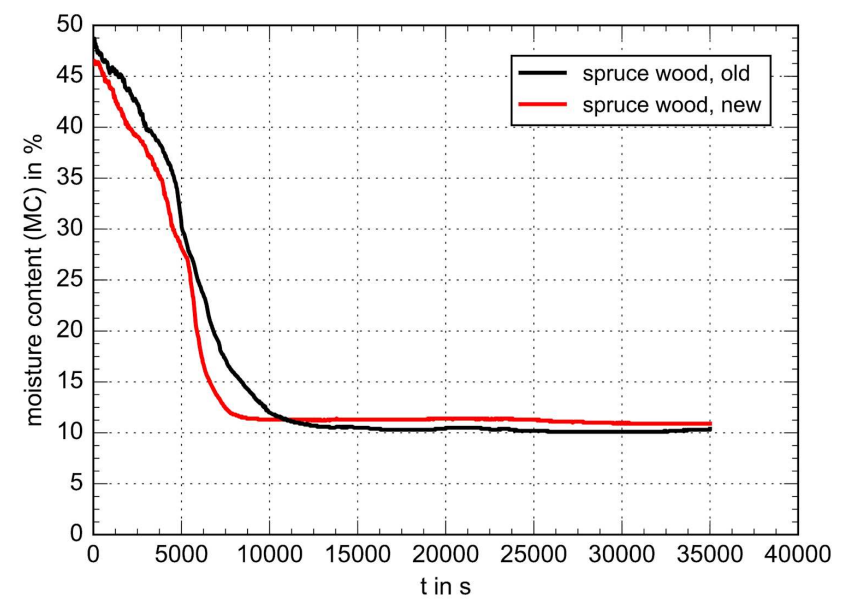

Fig. 15. Drying curves of old and new spruce wood.

When the drying curves in Fig. 15 are derived with respect to the time, the drying velocity of old and new spruce wood is obtained as shown in Fig. 16. The derivation of each of the curves was carried out in consideration to the data points to the left and to the right of each point. A curve smoothing was then applied, including the immediate surrounding of each data point as well. This concludes that the first and the last data points were disqualified from each handling procedure leading to a reduction of the initial data points.

In a first time interval up to $5000 \mathrm{~s}$, the drying rate of both wood samples is negative ( $\rightarrow$ moisture loss) and increasing, whereas the drying rate of the new wood is higher than that of old wood. After passing that interval, both wood specimens showed a decreasing drying rate but the drying acceleration to the EMC-point (curve section being parallel to the $x$-axis) for new spruce wood was higher, Fig. 16 (inserted figure). The drying acceleration 


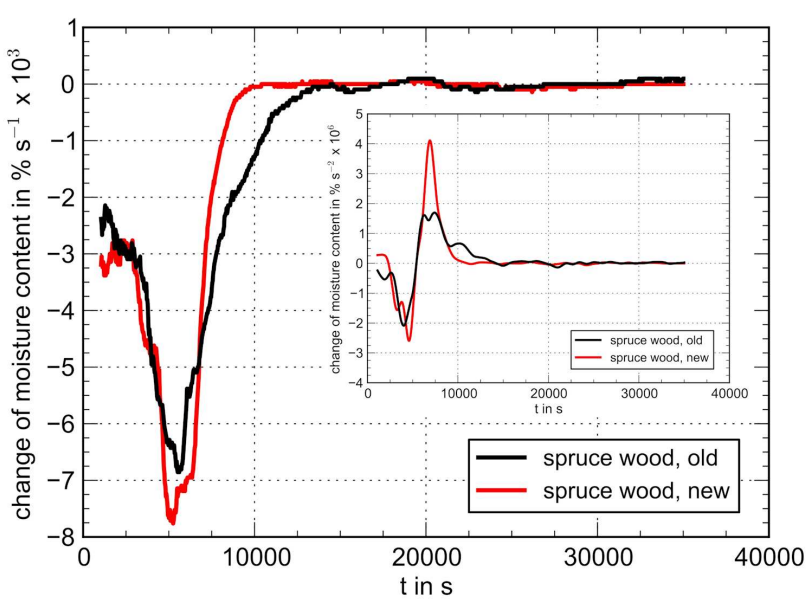

Fig. 16. Drying velocity curves of old and new spruce wood; inserted figure: smoothed drying acceleration curves.

curves of new and old spruce wood exhibited a minimum at about $5000 \mathrm{~s}$ and a maximum at about $7500 \mathrm{~s}$. Hence, the drying process of the investigated spruce woods is discontinuous but the process for old spruce wood seems to be more uniform when the differences between the extreme values of the drying acceleration curves are considered. This uniform behaviour is in accordance with the microscopic investigations of the darkness development (Fig. 14) of old spruce wood.

It is recognised from the drying acceleration curves that the new wood sample provides significantly higher acceleration values than the old one. This behaviour explains the rapid reaction to changes in the relative humidity which can be observed in practice when pianos made from new wood are exposed to varying humidity conditions. With concentration on the EMC-point, a permanent oscillation of the moisture content around this value is expected which corresponds to the high sensitivity of new wood towards a small change in the relative humidity. Due to the lower acceleration values of old wood, such a rapid reaction is not observable. In other words (from the musical-instrument manufacturer's point of view), the drying time of new spruce wood is longer, more unpredictable, and ultimately more unstable than that of old spruce wood. Although the EMC-point of new spruce wood is found in Fig. 15 at an earlier time value than that of old spruce wood, this point is regarded to be of low importance. Only when the oscillation of moisture content of new wood is significantly reduced with the help of a drying chamber, then it is assumed that the "real" EMC-point is obtained. It is characterised by a long-term (several weeks) and energy-intensive process.

The time consuming oscillating drying behaviour of new spruce wood contrasts with the generally more time stable behaviour of moisture release in old wood (Fig. 14). This could be seen as indicating that the amount of interactions of water molecules with biopolymers in new wood is higher which may result from the present structure.
Old wood has a higher tuning stability because the moisture-related change in shape of the old wood is only marginal. It is now hardly surprising to note that the tone colour is structure-dependent. In contrast to old wood, the cell wall components of new wood are still present and bind the water in the wood. This leads to a higher stability of the tone colour even when the climatic conditions change. We believe that the slower drying rate of both samples for times higher than $5000 \mathrm{~s}$ as seen in Fig. 16 is an indicator that the bound water loss starts.

It should be pointed out that the drying process was investigated after the intake of ink-mixed water (Fig. 14) and after the transfer of water vapour into the wood (by heating of water, see Sect. 2.1), Fig. 16. Consequently, the time dependence of the drying process should be influenced by the different methods of introduction of water into the wooden samples.

\subsection{Mathematical approximation of the drying curves}

Mathematical modelling and simulation design of biomass drying are widely used in the drying process in order to determine the most suitable operating conditions so that a drying equipment and drying chamber could be manufactured with better efficiency according to the desired expectations [42]. For this purpose, the moisture ratio, MR, is taken into account which is defined as [43]:

$$
\mathrm{MR}=\frac{\left(M_{t}-M_{e}\right)}{\left(M_{0}-M_{e}\right)} .
$$

$\mathrm{MR}$ is the non-dimensional moisture ratio, where $M_{t}$ is the moisture content at any time with $M_{t}=M C, M_{0}$ is the initial moisture content, and $M_{e}$ is the equilibrium moisture content of the sample. The individual moisture content is measured in gram water/gram dry solid.

There are a lot of drying models that aim to describe the experimental drying curve progression. An often used fitting equation is based on the drying curve model proposed by Page [44]:

$$
M R=\mathrm{e}^{-k t^{n}},
$$

where $k$ and $n$ are model parameters. In Fig. $17 \mathrm{MR}$ is plotted versus time $t$, whereas MR was calculated by applying the data from Fig. 15. A fit was carried out according to Eq. (6). The fit parameters $k$ and $n$ are shown in Table III. Considering the coefficient of determination, $r^{2}$, a close approximation to the experimental data could be obtained. The considerably different model parameters emphasise the different drying behaviour of both woods.

TABLE III

Model parameters using drying model of Page [44].

\begin{tabular}{c|c|c|c}
\hline \hline & $k$ & $n$ & $\begin{array}{c}\text { Coefficient of } \\
\text { determination, } r^{2}\end{array}$ \\
\hline $\begin{array}{c}\text { spruce wood, } \\
\text { old }\end{array}$ & $4.07 \times 10^{-9}$ & 2.22 & 0.99 \\
$\begin{array}{c}\text { spruce wood, } \\
\text { new }\end{array}$ & $5.51 \times 10^{-10}$ & 2.49 & 0.99
\end{tabular}




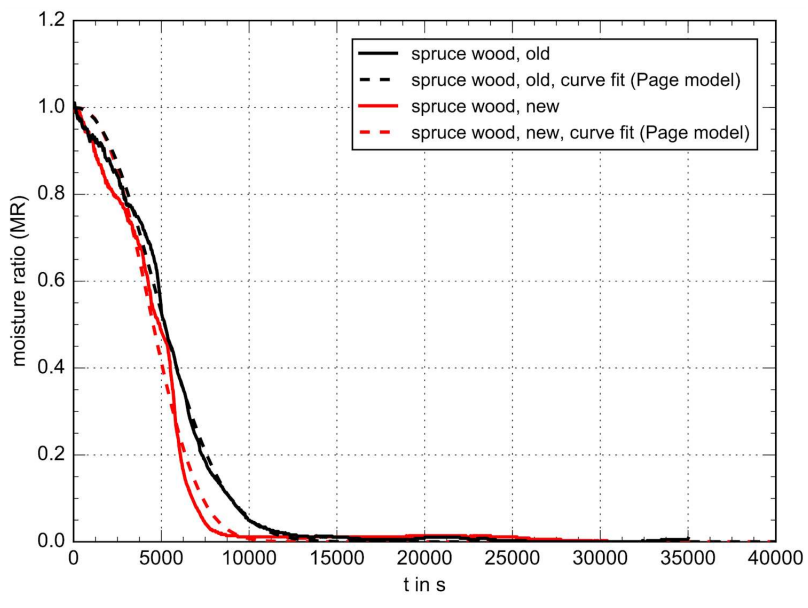

Fig. 17. Fitted drying curves (given as MR versus time) of old and new spruce wood.

Diffusion is the basic mechanism of moisture movement inside the drying material [45]. The calculation of effective water moisture diffusivity is given as (e.g. Ref. [46]):

$M R=\frac{8}{\pi^{2}} \sum_{n=0}^{\infty} \frac{1}{(2 n-1)^{2}} \exp \left(\frac{-(2 n-1)^{2} \pi^{2} D_{\mathrm{eff}} t}{4 L^{2}}\right)$

where $n \in \mathrm{N}_{0}, D_{\text {eff }}$ is the effective water diffusion coefficient, $t$ the time (commonly used in seconds in drying experiments) and $L$ is the wood's half thickness in meters. In Fig. 18, the decaying moisture curves were fitted in respect of Eq. (7). The water diffusion coefficient $D_{\text {eff }}$ is here understood as $D_{\text {eff, tot }}$ because the value is attributed to the total measuring time. For old spruce wood a total water diffusion coefficient of $D_{\text {eff, tot }}=1.50 \times 10^{-11} \mathrm{~m}^{2} / \mathrm{s}$ $\left(r^{2}=0.86\right)$ was calculated, whereas for new spruce wood $D_{\text {eff,tot }}=1.78 \times 10^{-11} \mathrm{~m}^{2} / \mathrm{s}\left(r^{2}=0.85\right)$ could be obtained. The effective water diffusion coefficient $D_{\text {eff }}$ does not distinguish between the different kinds of water transport (e.g. as vapour) during drying. The calculated values are very similar when the total measuring time is taken into account. However, a different time progression of moisture change was expected as obtained from the microscopic analysis (Fig. 14). Furthermore, the curves' fits did not coincide well with the experimental curves.

In addition, the courses of the drying velocity curves of old and new spruce wood (Fig. 16) called for improved identification of the statistical procedure because internal drying mechanisms appear to be different before and after the minimum of the drying velocity curves.

For this reason, the experimental data of Fig. 18 were divided into 108 sections and the effective water diffusion coefficient $D_{\text {eff }}$ of each section was calculated according to Eq. (7). The corresponding results are shown in Fig. 19.

In Fig. 20, the effective water diffusion coefficient $D_{\text {eff }}$ of each section is plotted versus time $t$ which is described here as the mean time value of each time section. For both spruce woods, a peak of the effective water diffu-

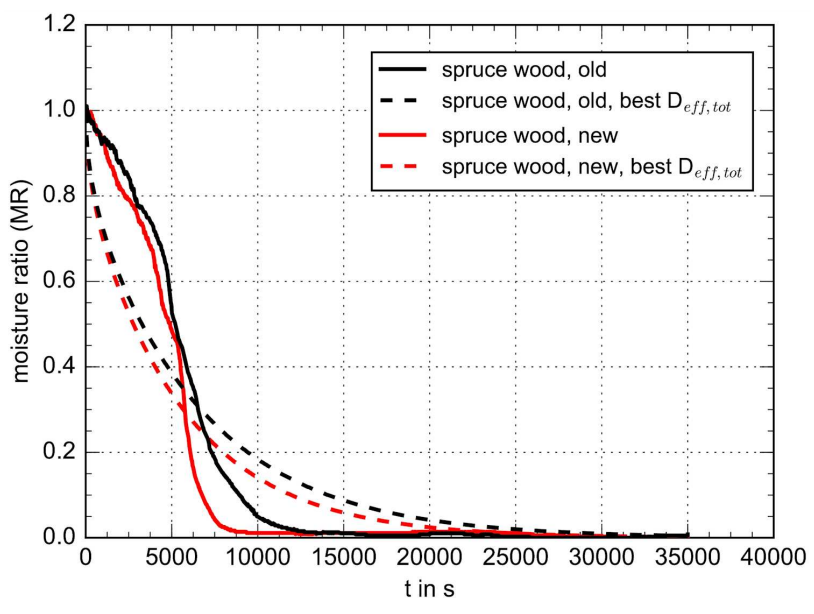

Fig. 18. Drying curves (given as MR versus time) of old and new spruce wood with determination of the total effective water diffusion coefficient $D_{\text {eff,tot }}$ of the total experimental curve.

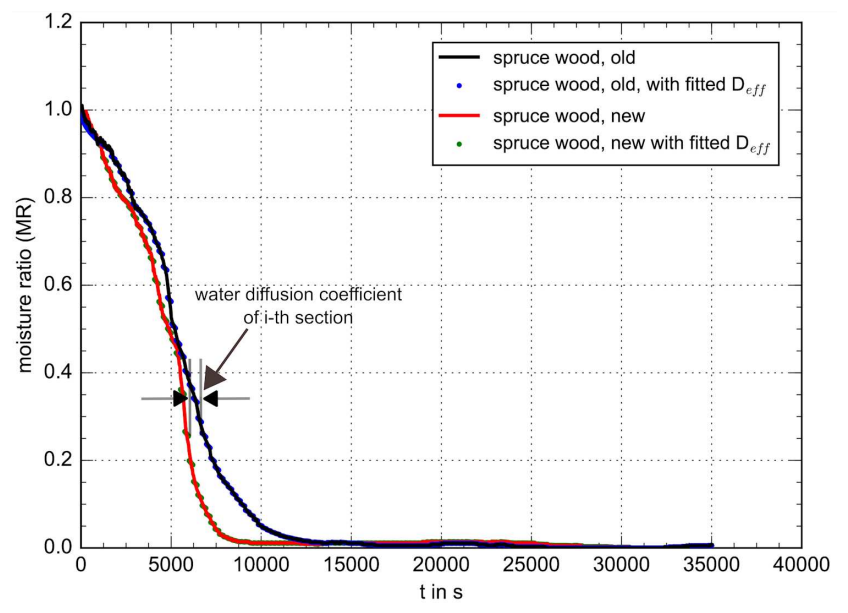

Fig. 19. Drying curves (given as MR versus time) of old and new spruce wood with calculation of the effective water diffusion coefficient $D_{\text {eff }}$ in different sections.

sion coefficient is obtained. It is obvious that the peak of the old spruce wood is different from that of the new one, i.e. it is shifted to higher times and is broader than that of the new spruce wood. This broader peak represents a broader distribution of diffusion times which means that several diffusion mechanisms may be considered to be active simultaneously. The observed behaviour in both woods could be attributed to a non-uniform water transport in the wood.

$\mathrm{Wu}$ and Berland [47] refer such a non-uniform behaviour to a limited mobility of the water molecules which can occur in complex media, for example within living cells. The mobility may be hindered by various factors, such as interactions with obstacles, transient binding events, or molecular crowding. 


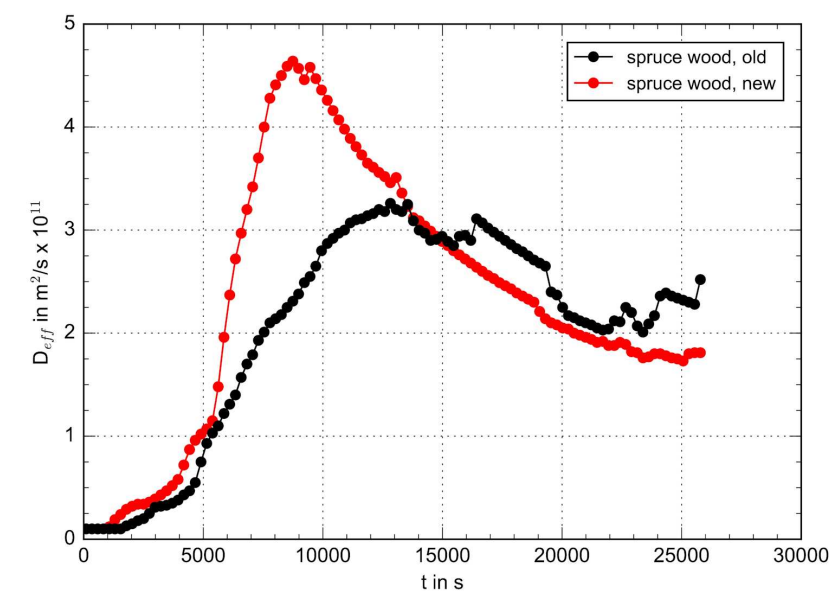

Fig. 20. Change of water diffusion coefficient $D_{\text {eff }}$ (calculated from different sections) with drying time $t$ of old and new spruce wood.

According to Fig. 16, the time for reaching the EMCpoint was about $7500 \mathrm{~s}$ for new and about $12500 \mathrm{~s}$ for old spruce wood. The individual maximum values of $D_{\text {eff }}$ in Fig. 20 occur nearly at the same times. It is assumed that this is an indication that bound water diffusion and vapour diffusion become dominant because the free water has left the lumens.

The effective water diffusion coefficient $D_{\text {eff }}$ values from Fig. 20 were plotted versus the moisture ratio, Fig. 21. As reported in literature (e.g. [48-51]) the water diffusion coefficient increases along with the increase of the moisture content, and subsequently of the moisture ratio (see Eq. (5)).

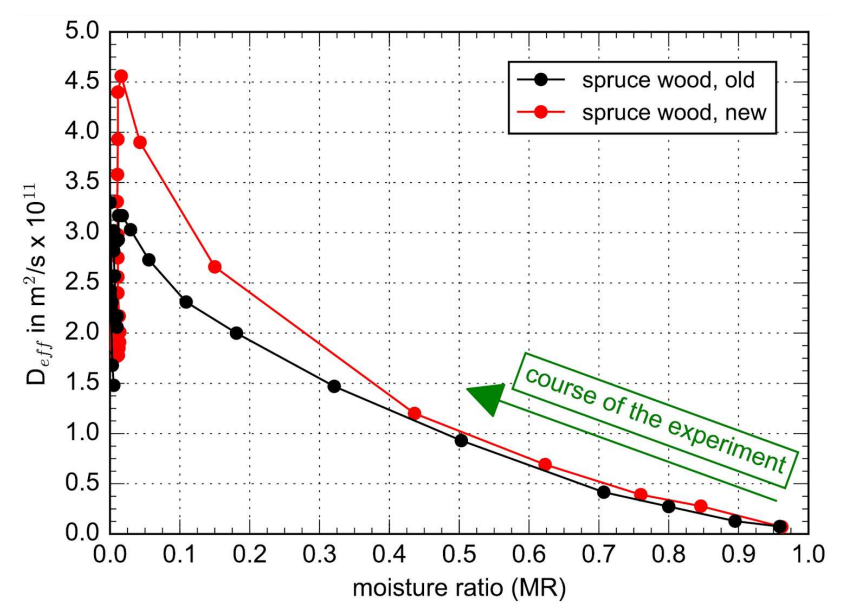

Fig. 21. Change of water diffusion coefficient $D_{\text {eff }}$ (calculated from different sections) with moisture ratio during drying process of old and new spruce wood.

However, Fig. 21 exhibits a decrease of $D_{\text {eff }}$ with increasing moisture ratio. The increase of $D_{\text {eff }}$ with rising moisture content, frequently mentioned in the literature, is not a general rule because it was found that differ- ences can exist between wood species and their anatomical directions. For example, diffusion transverse to the fibres is significantly smaller than diffusion in fibre direction [52]. Moisture diffusion coefficient decreasing together with the moisture of the material in the case of pine in the radial direction was found by Olek and Weres [53]. Perkowski et al. [54] emphasise that the transport of moisture in wood is a very complicated process, which is a result of different diffusion mechanisms. Diffusion of water vapour (mostly in the cell lumens and also in cavities between microfibrils or in intercellular spaces), diffusion of bound water (inside walls and through the pits) and adsorption and desorption could be responsible for the value of the diffusion coefficient below the saturation point of fibres. The presence of different diffusion mechanisms was already taken into consideration for the interpretation of the course of $D_{\text {eff }}$ in Fig. 20.

The ways in which water moves through wood are by (1) capillary flow of water in the cell cavities (above the fibre saturation point), (2) diffusion as hygroscopic water (bound water) in the cell walls (below the fibre saturation point), (3) diffusion as water vapour through the air in the cells and through the openings in the cell walls (below fibre saturation point) and (4) combinations of two or all of the three methods. During drying, the moisture content of a wood sample increases towards the centre which may be green (above fibre saturation point). All mentioned methods would cause drying at the same time in that sample $[55,56]$.

In order to point to the complexity of the drying process, we refer to the studies of Stamm [57] who discussed the drying of green wood which contained appreciable amounts of air in the cell cavities. In that case, the rate of free water movement above the fibre saturation point is controlled by the moisture gradient below the fibre saturation point. If the free water moves faster than the bound water and water vapour below the fibre saturation point, the moisture content near the wet line would tend to build up. This can only be realised by a compression of the air bubbles in the fibre cavities near the wet line leading to a decrease rather than increase in size. Under such conditions, the flow would tend to be reversed. Against this background, Stamm [57] emphasises that the moisture movement above the fibre-saturation point, though not itself a diffusion phenomenon, will thus be controlled by the diffusion below the fibre saturation point and will appear as if it were a diffusion phenomenon.

Based on the presence of air bubbles in the fibre cavities and various water transport mechanisms taking place simultaneously, a simplified model for the drying process in spruce wood was developed. In Fig. 22, a water transportation model which could explain the observed behaviour of the water diffusion coefficient with changing moisture content is illustrated.

According to that model, water molecules forming clusters in a wood sample try to leave the water by diffusion from the middle of the sample to its edge during the drying process (green arrows). Diffusion takes 

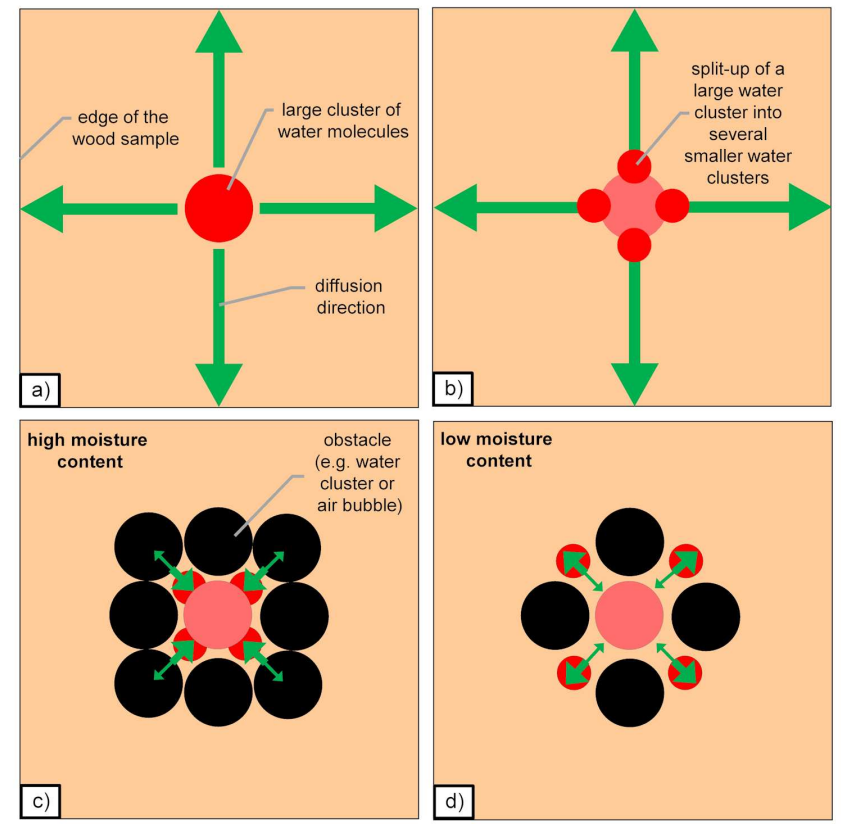

Fig. 22. Transportation model of water in spruce wood depending on the moisture content.

place uniformly (approximately spherically) in all directions (Fig. 22a) driven by a corresponding potential gradient. The water cluster has the tendency to divide into smaller clusters in order to diffuse easier in all directions (Fig. 22b). On the way to the edge of the wood sample, the water transport is prevented (green double arrows) by obstacles (e.g. other water clusters or air bubbles) whose amount is high in case of high moisture content at the beginning of the drying process (Fig. 22c). As a result, the potential gradient is not high enough to overcome the barriers caused by the obstacles (thicker half of the green double arrow). With decreasing moisture content (Fig. 22d), the amount of obstacles are decreasing and the water transport becomes easier which characterises a higher water diffusion coefficient. This means that the corresponding potential gradient becomes higher and thus, the present barriers caused by obstacles could easier be overcome. It can be concluded that the higher the moisture content of the wood, the lower the diffusion coefficient, as observed in Fig. 21.

In Fig. 23, the dependence of the effective water diffusion coefficient $D_{\text {eff }}$ on time and on the moisture ratio is shown. Moreover, the mean value of the water diffusion coefficient $D_{\text {eff }}$ from the individual sections is plotted. For old spruce wood, the mean value is $D_{\text {eff }}=2.05 \times 10^{-11} \pm 1.02 \times 10^{-11} \mathrm{~m}^{2} / \mathrm{s}$, and for new wood, $D_{\text {eff }}=2.33 \times 10^{-11} \pm 1.29 \times 10^{-11} \mathrm{~m}^{2} / \mathrm{s}$. In consideration of the given standard deviation, there is practically no difference between $D_{\text {eff }}$ of both woods which could be obtained by the previous calculation of the total water diffusion coefficient over the total measuring time (see Fig. 18). $D_{\text {eff }}$ has the same order as $D_{\text {eff,tot }}$.

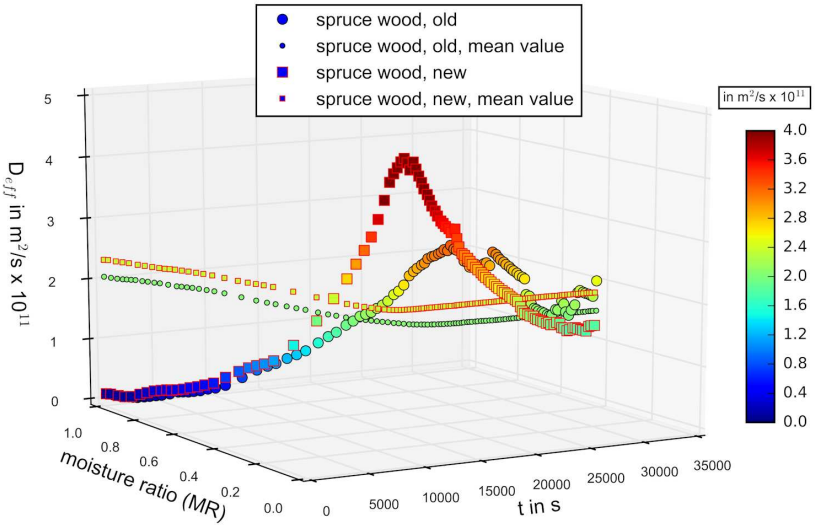

Fig. 23. Change of water diffusion coefficient $D_{\text {eff }}$ (calculated from different sections) with moisture ratio and drying time $t$ of old and new spruce wood. The mean value of $D_{\text {eff }}$ is added to the graph.

From this point of view, the calculation methods of the mean value of the water diffusion coefficient of biological cells for a long time range as often used in literature (see Eq. (7)) is physically legitimate, but not for smaller time intervals when the moisture content changes.

The MR-values of Fig. 21 were re-calculated to the current moisture content $\mathrm{MC}$ which is according to Eq. (5) equivalent to $M_{t}$. The drying curves were then fitted using an exponential decay fit as shown in Fig. 24, which represented a good approximation to the experimental data. The obtained decay constant value of new wood is almost twice higher than that of old wood. This different behaviour of moisture release has to be taken into account by the production of musical instruments or the storage of tonewood. Against this background, it becomes clear why in the practice of wood drying of green wood, moisture must be added to the drying process in order to slow the drying process and thus, to reduce the decay constant value.

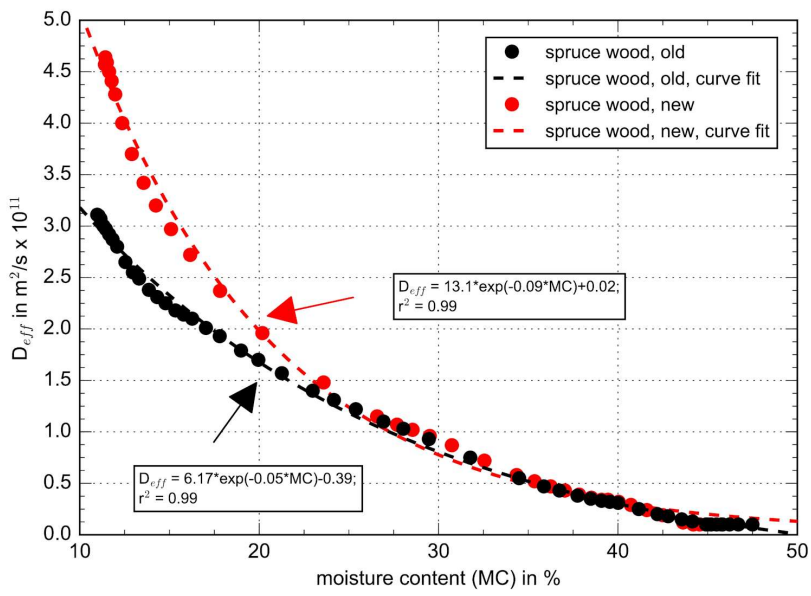

Fig. 24. Water diffusion coefficient $D_{\text {eff }}$ (calculated from different sections) as a function of the MC including the coefficient of determination $\left(r^{2}\right)$. 
Burch et al. [58] measured the diffusion coefficient of a $12 \mathrm{~mm}$ thick fibre board. They observed a decrease in diffusion coefficient with increase in moisture content and attributed the difference to the dominant moisture transfer mechanism in the material. This dominant moisture transfer mechanism might be a water-vapour diffusion through air-filled pore spaces, while bound water diffusion may play a more important role in solid wood $[59,60]$. The governing process of water-vapour diffusion was also found by Siau [61].

In general, it can be concluded that the water diffusion coefficient could be both a steady-state and a transient value [20]. While the influence of the local driving potential gets lost in long time intervals, it becomes dominant when $D_{\text {eff }}$ is measured for short time ranges (Fig. 19).

\subsection{Results from damping measurements}

\subsubsection{Frequency-dependent damping measurements}

In Fig. 25, the material damping in terms of the loss factor $\tan \delta$ of new and old spruce wood is plotted versus frequency at a constant deflection strain $\varepsilon$ of $50 \%$ of the specimen thickness $h$. It can be observed that there is almost no influence of the frequency value (frequency range $0.3 \mathrm{~Hz}$ to about $70 \mathrm{~Hz}$ ) on the material damping of both specimens at about $8 \%$ moisture content. The independence of damping for old and new spruce wood on the chosen frequency range was also found at different moisture contents.

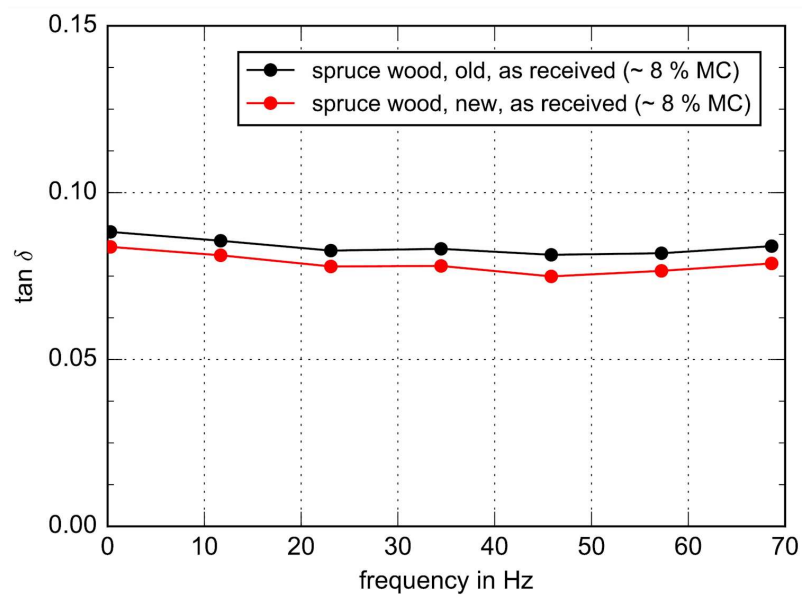

Fig. 25. Frequency-dependent damping of old and new spruce wood at a moisture content of nearly $8 \%$ and a deflection strain $\varepsilon$ of $50 \%$ of the specimen thickness $h$.

Such a frequency-independent damping could as well be observed for hardwood (maple wood) in the frequency range of 2 to $200 \mathrm{~Hz}$ [62]. Flexural vibrations on pine wood showed a frequency-independent damping in the range of $125-400 \mathrm{~Hz}$ [63]. In the work of Rohloff [64], a frequency-independent damping of spruce wood starting at approximately $80 \mathrm{~Hz}$ was established, Fig. 26.

Krüger and Rohloff [39] performed transversal vibrations on spruce wood and found a frequency-independent

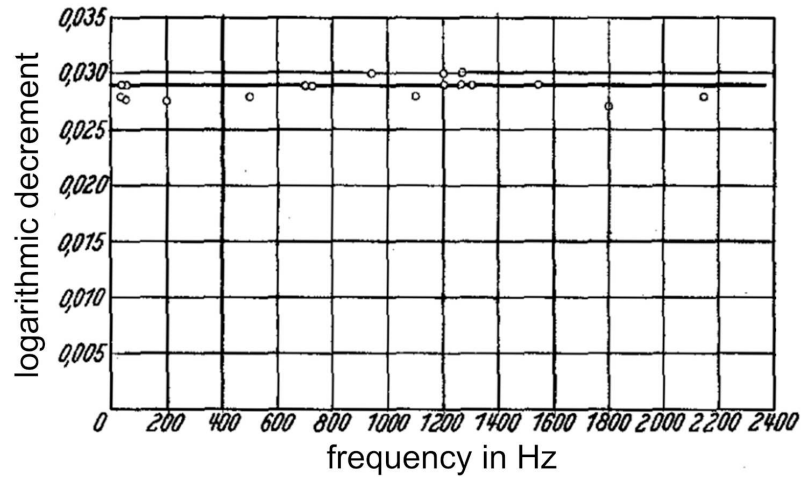

Fig. 26. Frequency-dependent damping of spruce wood; after Ref. [64].

damping in the range from 10 to $700 \mathrm{~Hz}$. Compared to other woods (oak, pine, maple), the damping of spruce wood was found to be the smallest in this frequency range. The results of the present paper show that the frequency independence of spruce wood damping should even be valid for values far below $1 \mathrm{~Hz}$.

Amada and Lakes [65] found a frequency-independent damping of wet and dry bamboo wood in the frequency range from about $1 \mathrm{~Hz}$ to nearly $100 \mathrm{~Hz}$ and attributed the viscoelastic damping to molecular motions in the biopolymer constituents, specifically cellulose and lignin [66]. Concerning the fact that the damping value was relatively small and no peak was measured, they attributed their results to highly constrained molecular chains. Due to the marginal influence of moistening on the damping, they concluded that water did not plasticise the polymer chains, suggesting a highly constrained molecular organisation [65].

Mania et al. [67] investigated the modal frequencies and damping obtained from impact modal testing for spruce wood of different quality. Although their damping measurements were frequency-independent within the accuracy limits of the measurements, they pointed out that, at least for frequencies over $200 \mathrm{~Hz}$, the value of damping can slightly increase which was taken from findings of Ouis [68]. Mania et al. [67] classified spruce wood in resonance and non-resonance ones and emphasised this behaviour as a specific property of spruce wood.

Damping can be caused by the transversal heat flow in bent beams from compressed to extended regions or due to heat exchanges with the environment. This transversal heat flow due to the thermoelastic effect is more dependent on intrinsic physical properties than on the structure and is probably the only effect which exactly produces a Debye peak [69]. When the time of stress reversal equals the time necessary for heat flow from the compressed to the extended regions, the damping exhibits a maximum. The frequency $f_{0}$ at which this maximum occurs is dependent on the thermal diffusivity $D_{t}$ and the sample thickness $a . D_{t}$ is a measure of how quickly a material can absorb heat from its surroundings. The value $f_{0}$ can 
be calculated as $f_{0}=\frac{\pi D_{t}}{2 a^{2}}[70]$. With $a=1.1 \mathrm{~mm}$ and $D_{t} \approx 1.8 \times 10^{-7} \mathrm{~m}^{2} / \mathrm{s}$ (for Sitka spruce wood at $15^{\circ} \mathrm{C}$ and $12 \%$ moisture content [10]) a value of $f_{0} \approx 0.2 \mathrm{~Hz}$ is obtained. The lowest frequency applied in the frequencydependent damping measurements was $0.3 \mathrm{~Hz}$ and therefore higher than the calculated $f_{0}$. A peak due to thermoelastic damping was not measured (Fig. 25), although a marginal influence of a certain peak width could have been expected. It can be stated that no particular loss mechanism was observed in the chosen frequency range.

\subsubsection{Strain-dependent damping measurements}

Strain-dependent damping measurements were carried out on old and new spruce wood. Here, it is taken into account that the damping was found to be nearly frequency-independent in the range from 0.3 to about $70 \mathrm{~Hz}$ (see previous section). Hence, strain-dependent damping measurements at different frequencies are assumed to be comparable with each other.

Figure 27 shows exemplarily the strain-dependent damping measurements on old spruce wood at a frequency of $12 \mathrm{~Hz}$ and different moisture contents. All damping curves can be divided into a strain-independent and a strain-dependent part, which is well known for metals due to dislocation motion $[71,72]$. The same straindependent damping behaviour could be observed for samples made from new wood, Fig. 28.

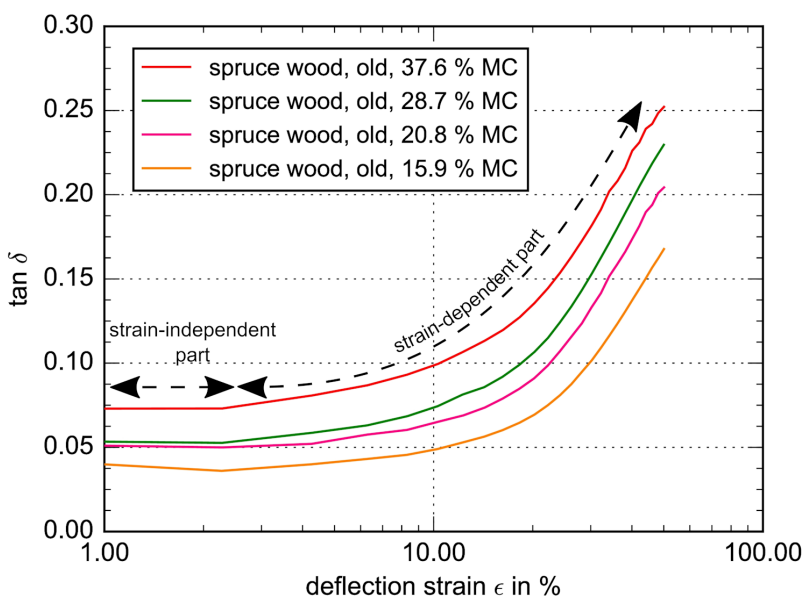

Fig. 27. Strain-dependent damping of old spruce wood at $12 \mathrm{~Hz}$ and different moisture contents.

A corresponding curve progression for wood was measured by Yeh et al. [21]. Such a strain-dependent behaviour can be regarded as being dominated by fibres acting as flexible structure components. The strong influence of the cellulose microfibrils on the material damping was shown by Ono and Norimoto [26]. Nevertheless, measurements of strain-dependent damping of wood seem to be rarely performed in literature.

In the manufacture of musical instruments, stretching is used at various points (curvature of the soundboard, curvature of the ribs, bending of the curved inner wall and outer wall of the grand pianos). Narrow radii in-

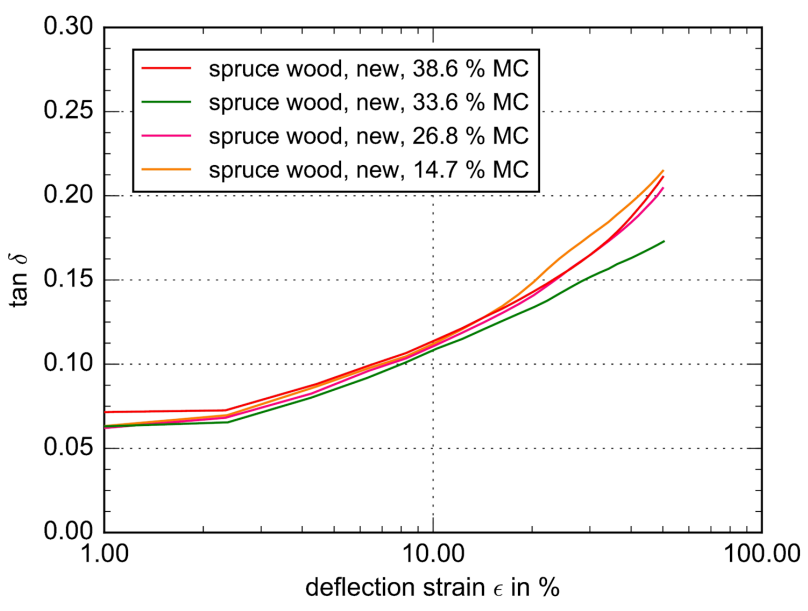

Fig. 28. Strain-dependent damping of new spruce wood at $12 \mathrm{~Hz}$ and different moisture contents.

ducing higher material strain can increase the damping whereas large radii lead to reduced damping, as expected from Figures 27 and 28.

According to Fig. 27, the damping of old spruce wood decreases with decreasing moisture content. This means that, in contrast to the frequency, the moisture content has a significant influence on the damping behaviour of the old spruce wood. This could be an indication to why old instruments change their tone colour easily with climate changes. As illustrated in Fig. 28, there seems to be no significant influence of the moisture content on $\tan \delta$ in new spruce wood, which could be attributable to the absence of chemically degraded biopolymers in the wood structure. Therefore, new instruments do not usually show such a tone colour alteration.

As reported by Fengel [73], a certain decrease in the hemicellulose content was found in pinewood from 290 and 365 years old roof constructions, which were stored under atmospheric conditions, while the cellulose percentage here did not differ from that in new dry wood.

Noguchi et al. [74] investigated the vibrational properties of aged wood (121 to 296 years old) which were compared with those of recently cut wood. The vibration measurements were performed in the resonance frequency range of 40 to $120 \mathrm{~Hz}$. The aged wood showed lower damping than the new wood. This was attributed to structural changes in the wood cell during ageing. With respect to Fig. 27 and Fig. 28, the strain-independent damping value of old wood is on average lower than the corresponding value of new spruce wood which correlates to the findings of Noguchi et al. [74].

Tomasetti et al. [75] investigated samples of spruce, fir, and larch by means of thermogravimetric analysis. According to their interpretation, ageing is connected with an increase of the percentage of lignin content caused mainly by the decrease in cellulose. The hemicellulose content of spruce was found to diminish with age. In specimens older than 210 years, about one third of hemicelluloses were lost. 
By comparing the structure of new and old wood in asreceived condition (Fig. 13), the mentioned degradation process in old spruce wood could be assumed due to its brighter and clearer micrograph than that of the new wood specimen using the same optical adjustments. This could be a hint for physical and chemical changes in the wood with time.

Successively applied strain-dependent damping measurements at $12,22,33,35$, and $75 \mathrm{~Hz}$ and slightly varying moisture content were taken into account. This measurement series was repeated five times. The time needed for each series was about $1200 \mathrm{~s}$. The total measuring time of about $6000 \mathrm{~s}$ was not critical for both woods concerning the individual change of the moisture content and of the diffusivity behaviour, which can be expected for times being distinctly higher than $6000 \mathrm{~s}$ (see Fig. 20).

Considering the frequency-independence of the material damping as found in Fig. 25, each measurement series was supposed to be performed at the same frequency. It was then possible to select the damping value $(\tan \delta)$ at a certain deflection strain $\varepsilon$ in order to calculate the attributed average damping value and the corresponding standard deviation as well as the average of the moisture content values from all five measurement series.

Regarding the total strain range of the damping measurements (see Fig. 27 and Fig. 28), the above mentioned procedure was applied at three deflection strain values. Figures 29 and 30 show the damping in terms of $\tan \delta$ as a function of the $\mathrm{MC}$ at different deflection strains $\varepsilon$ of $2.3 \%, 20.2 \%$ and $40.1 \%$ of old and new spruce wood. For old spruce wood it becomes clear that (a) $\tan \delta$ decreases with decreasing moisture content and (b) at constant moisture content, $\tan \delta$ increases with rising deflection strain $\varepsilon$ which was expected from Fig. 27 .

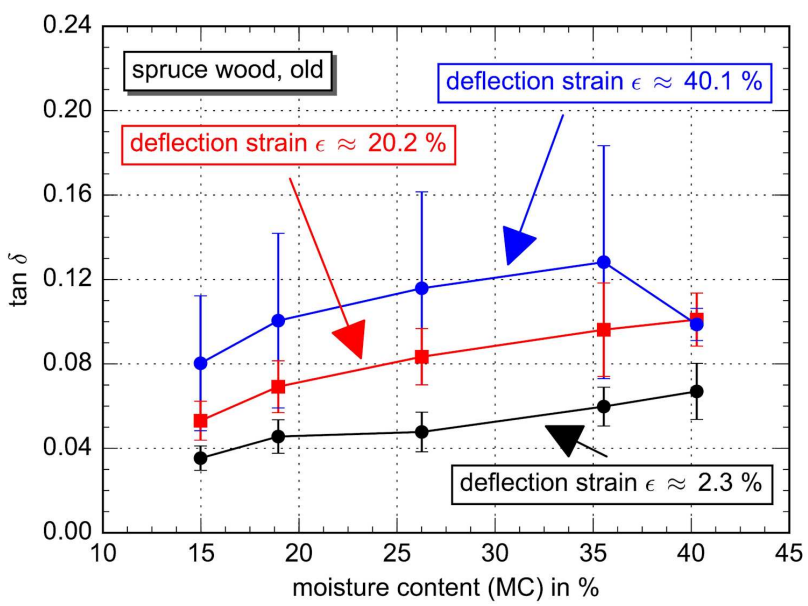

Fig. 29. Damping of old spruce wood as a function of $\mathrm{MC}$ at different deflection strains $\varepsilon$ (percent of the sample thickness).

Moreover, the standard deviation of $\tan \delta$ seems to jump up at higher deflection strains $\varepsilon$, which can be attributed to the formation of further damping mechanisms at different moisture contents. The situation is different for new spruce wood, Fig. 30. Within the accuracy limits of the measurements, the obtained material damping of new spruce wood is rather independent of the moisture content. Therefore, it is plausible why pianos made from new wood show only minor changes in the tone colour when the relative humidity and thus the wood moisture change. However, an alteration of the moisture could lead to a slight curvature of the soundboard. This may cause a mechanical stress which influences the tone colour.

A strong impact of the deflection strain $\varepsilon$ on $\tan \delta$ is appearing as well in new spruce wood. The material damping of new spruce wood is generally higher than that of old spruce wood. At ambient temperature with $55 \%$ relative humidity, the expected moisture content of spruce wood is about $12 \%$ [76]. A moisture content around this value is sought when a piano is tuned before being played in concerts. The lower damping of old wood at a measured moisture content of nearly $15 \%$ (Fig. 29) suggests that the duration of the oscillation and thus the duration of the sound will be longer and the amplitude of vibration can be increased without expecting a significant higher damping. From these results, it is quite understandable why guitar builders and violin makers attach great importance to deposited wood.

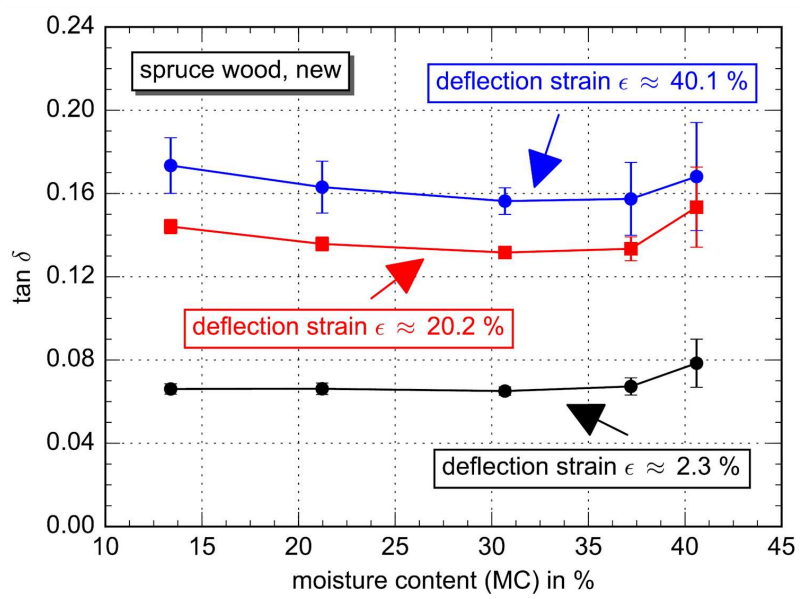

Fig. 30. Damping of new spruce wood as a function of the $\mathrm{MC}$ at different deflection strains $\varepsilon$ (percent of the sample thickness).

The increase of the wood damping with increasing moisture content was shown by Dunlop [6] who interpreted the damping by the motion of water molecules themselves or motions of some molecular parts of the wood structure which are affected by the presence of water.

The characteristics of the strain-dependent damping curves of old and new wood (Fig. 27 and Fig. 28) is well known for crystalline material. Thus, it is assumed that wood possesses the behaviour of a partial crystalline material as proposed by Becker and Noack [77]. According to their measurements, groups of molecules from cel- 
lulose, hemicellulose, and lignin are responsible for the moisture impact on damping. They suspect that water molecules lead to variations in the distance between the group molecules, change their mobility, the state of orientation of the molecules as well as of the dipole moment of polar groups.

Sadoh [78] investigated the mechanical damping on wood swollen with formamide and a series of glycols, at frequencies of 0.02 and $0.5 \mathrm{~Hz}$ as a function of temperature. Due to his opinion, small molecules of the swelling agent penetrate into the cell walls during wood swelling and expand distances between polymer segments composing the wood substances. As a consequence, the interaction forces between the molecules, originally developed between adjacent segments, are reduced leading to an increase of the mobility of the polymer segments. Consequently, the mechanical loss would rise which is confirmed in Fig. 29 by an increase of $\tan \delta$ for old spruce wood with rising moisture content. However, new spruce wood seems to be more dependent on the applied deflection strain than on the moisture content. Both wood specimens differ in their chemical composition, e.g. because of the loss of hemicellulose in aged wood [75]. The hemicelluloses are mostly linear molecules, containing mainly hydroxyl and carboxyl groups. Water has a strong affinity to these hydrophilic groups [79]. The crystalline cellulose microfibrils can be considered to be unaffected by water. Therefore, we assume that the crystalline cellulose is more dominant in new spruce wood.

Finally, it is worth mentioning that the discussed results on the damping behaviour of wood can differ strongly from each other. Schniewind [80] reviewed the progress in the study of the rheology of wood and compared findings of various authors in one decade. He underlined that there is an almost complete lack of generalised quantitative information. According to his research, much information that developed so far still do not fit into any cohesive framework.

\section{Conclusions}

In the manufacture of musical instruments, the most important tonewood is spruce which is the preferred construction material for upright and grand pianos. The moisture content has a significant influence on the acoustic behaviour of such wooden instruments. Based on the knowledge of wood moisture release development, there could be a potential for saving energy, since the drying machines used for the preparation of tonewood would run with less energy.

In order to study that moisture influence, the individual drying behaviour of nearly 130 years old spruce and new spruce wood was investigated by transmitted light microscopy. Moreover, measurements on the release of moisture using a moisture meter as well as frequencydependent and strain-dependent damping measurements were performed. All measurements were carried out at room temperature and a relative humidity of about $58 \%$.
The microscopic analysis suggested that old wood consists of naturally degraded cell components. The rate of natural moisture loss in the wood was used to determine the individual drying process. This could be interpreted from the darkness change of the microscopic images due to the time-dependent concentration change of ink-mixed water, which had been dripped into the wood before. It became obvious that the velocity of moisture release for the old spruce specimen is constant in contrast to the corresponding behaviour of the young sample. The moisture loss of new wood was interrupted by "intermediate stages" which had to be overcome.

The moisture content measurements accompanying the drying process of spruce wood showed that the total drying course of wood can be characterised by episodes with phases of more severe or weaker drying activities, whereas the drying velocity of the new spruce was generally higher and relatively less continuous than that of the old one. This could be emphasised by calculating the individual drying acceleration curve. In order to study the time dependence of the moisture loss of both spruce woods, the drying curves were fitted according to the drying model of Page. This model characterised the drying curve progression in a good approximation.

Due to the fact that moisture release is a diffusioncontrolled process, the effective diffusion coefficient $D_{\text {eff }}$ was calculated to describe the drying process more detailed. A mean value of approximately $D_{\text {eff }}=1.6 \times$ $10^{-11} \mathrm{~m}^{2} / \mathrm{s}$ for spruce was obtained. This calculation was applied to the total drying time (curve fitting) and led to an insufficient adaptation to the measuring curves.

Based on the assumption of different internal drying mechanisms that do not occur simultaneously with the same dominance (which could be expected from the interpretation of the drying velocity curves), the drying curve was divided up into time sections. Each time section was then fitted in the same way as performed for the total measuring time. The received $D_{\text {eff }}$ of each section was plotted versus the time. A peak developed for both woods which was lower and broader for old wood. Furthermore, the peak value was shifted to higher times compared to the new spruce wood curve. It can be assumed that a broader peak represents a distribution of diffusion times, from which the time-dependent dominance of several diffusion mechanisms could be considered.

An increase of the diffusion coefficient $D_{\text {eff }}$ with decrease of moisture content was found. This result was attributed to the presence of different diffusion mechanisms in the wood, especially below the saturation point of fibres. Diffusion of water vapour (mostly in the cell lumens and also in cavities between microfibrils or in intercellular spaces), diffusion of bound water (inside walls and through the pits) and adsorption and desorption can generally be held responsible for the current value of the diffusion coefficient $D_{\text {eff }}$. A mean value for spruce wood was obtained as $D_{\text {eff }}=2.2 \times 10^{-11} \mathrm{~m}^{2} / \mathrm{s}$ after dividing the drying curve into several time sections which represents the consideration of these different diffusion mech- 
anisms. It becomes clear that, while the influence of the local driving potential gets lost in long time intervals, it becomes dominant when $D_{\text {eff }}$ is measured for short time ranges.

A simple transport model of water motion in spruce wood was introduced following the approach that water transportation can be hindered by obstacles like water clusters or air bubbles in the wood.

Damping measurements on new and old spruce wood showed that the material damping which was indicated in terms of the loss factor $\tan \delta$ was almost frequencyindependent in the range from 0.3 to about $70 \mathrm{~Hz}$. Straindependent damping measurements on both woods were carried out at a constant frequency and varying moisture content. All damping curves could be divided into a strain-independent and a strain-dependent part, which is well known for metals when dislocation segments break away from pinning points. Therefore, for an explanation of the results, a breaking away mechanism was also expected here.

The peak frequency of the thermoelastic effect, which could have an influence on the material damping, was calculated. This value was below the applied frequency range of the damping measurements and could be excluded.

In contrast to the frequency, the moisture content had a significant influence on the damping behaviour of the old spruce wood. This was attributed to the wood structure containing chemically degraded biopolymers (e.g. decrease in hemicellulose) which can no longer pin the water molecules (breaking away mechanism). The results show that the damping of new wood is less sensitive to moisture content changes, which corresponds to a stable tone colour.

The sound quality of a musical instrument is determined by the fundamental tone and corresponding partial tones. In contrast to old spruce wood, some of these partial tones get lost in new spruce wood due to its generally higher damping. New spruce wood is therefore used in simple and cheaper instruments because the optimisation of the sound quality is of less priority. Based on its generally lower damping, old or well-stored wood has the advantage of being used in high-quality instruments designed for music experts who attach importance to the optimisation of the sound quality.

As a result of the structure-induced ageing, one cannot easily deduce from today's sound of old wood (full sound, warm sound, sonorous sound, bright sound) how it sounded in its earlier stages. It must not remain unmentioned that the instrument is a complex system assembled by various parts which have an individually limited construction stability. This could also have a substantial effect on the sound quality.

\section{Acknowledgments}

Prof. Dr. Jürgen Göken gratefully acknowledges the financial support of the German Research Foundation (DFG, www.dfg.de; DFG-reference number: INST 21572/5-1 FUGG).
The authors would also like to express their deep gratitude to the company Holzwerke Strunz GmbH \& Co. KG (Pocking, Germany) for the free provision of the young spruce samples.

\section{References}

[1] N.H. Okoye, A.N. Eboatu, R.U. Arinze, N.L. Umedum, P.I. Udeozo, O.A. Ogbonna, IOSR J. Appl. Chem. 7, 76 (2014).

[2] R.H. Falk, in: Wood Handbook - Wood as an Engineering Material. United States Department of Agriculture, Forest Service, Forest Products Laboratory, General Technical Report FPL-GTR-190, Madison (WI) 2010, Ch. 1.

[3] N. Bogusch, Wood Materials and Wood Pests, Germany, 2005 (access on 27th December 2016).

[4] T. Conners, Products Made from Wood, Department of Forestry, Fact Sheet FORFS 02-02, University of Kentucky, College of Agriculture (access on 29th December 2016).

[5] U.G.K. Wegst, Am. J. Bot. 93, 1439 (2006).

[6] J.I. Dunlop, Wood Sci. Technol. 12, 49 (1978).

[7] S. Yoshikawa, C. Waltham, in: Proc. Int. Symp. on Musical Acoustics, ISMA, Le Mans (France), 2014, p. 281.

[8] J. Göken, H. Arends, H. Brink, ARPN JEAS 9, 1983 (2014).

[9] R.B. Miller, in: Wood Handbook: Wood as an Engineering Material, U.S. Department of Agriculture, Forest Products Laboratory, General Technical Report FPL-GTR-113, Madison (WI) 1999, Ch. 2.

[10] J. Moore, Wood Properties and Uses of Sitka Spruce in Britain, Forestry Commission Research Report. Forestry Commission, Edinburgh 2011, p. 1.

[11] R.A. Eaton, M.D.C. Hale, Wood: Decay, Pests and Protection, Chapman \& Hall, London 1993.

[12] CHEM-E2105 - Course: Wood and Wood Products, lecture by M. Hughes, Wood-water relationships I, 2016, Aalto University, Finland.

[13] J.E. Reeb, Wood and Moisture Relationships, Oregon State University Extension Service, 1995.

[14] N. Zhang, S. Li, L. Xiong, Y. Hong, Y. Chen, Model. Simul. Mater. Sci. Eng. 23, 1 (2015).

[15] J. Nagyvary, J.A. DiVerdi, N.L. Owen, H.D. Tolley, Nature 444, 565 (2006).

[16] H. Yano, H. Kajita, K. Minato, J. Acoust. Soc. Am. 96, 3380 (1994).

[17] H.-C. Tai, G.-C. Li, S.-J. Huang, C.-R. Jhu, J.H. Chung, B.Y. Wang, C.-S. Hsu, B. Brandmair, D.-T. Chung, H.M. Chen, J.C.C. Chan, Proc. Natl. Acad. Sci. 114, 27 (2017).

[18] S.L. Berry, M.L. Roderick, New Phytol. 168, 25 (2005).

[19] H.L. Frandsen, Wood Science and Timber Engineering, Paper No. 1 (annual report), Dept. of Building Technology and Structural Engineering, Aalborg University, Denmark 2005.

[20] B. Time, Ph.D. Thesis, Department of Building and Construction Engineering, Norwegian University of Science and Technology, Trondheim 1998. 
[21] C.-T. Yeh, B.J. Hartz, C.B. Brown, J. Sound Vibrat. 19, 411 (1971).

[22] B.J. Lazan, Damping of Materials and Members in Structural Mechanics, Pergamon Press, Oxford (UK) 1968.

[23] K.S. Kwan, Ph.D. Thesis, Virginia Polytechnic Institute and State University, Blacksburg 1998.

[24] M.F. Ashby, Materials Selection in Mechanical Design, Butterworth-Heinemann, Oxford 2005.

[25] I.S. Golovin, Metall. Mater. Trans. A 25, 111 (1994).

[26] T. Ono, M. Norimoto, Jpn. J. Appl. Phys. 22, 611 (1983).

[27] C. Jonsson, Detection of Annual Rings in Wood, Thesis project, LiU-ITN-TEK-A-08/122-SE, Department of Science and Technology, Linköping University, Norrköping 2008.

[28] D. Sandberg, J. Johansson, Holztechnologie 48, 5 (2007).

[29] S.V. Glass, S.L. Zelinka, in: Wood Handbook - Wood as an Engineering Material, United States Department of Agriculture, Forest Service, Forest Products Laboratory, General Technical Report FPL-GTR190, Madison (WI) 2010, Ch. 4.

[30] W. Simpson, A. TenWolde, in: Wood Handbook Wood as an Engineering Material. United States Department of Agriculture, Forest Service, Forest Products Laboratory, General Technical Report FPLGTR-113, Madison (WI) 1999, Ch. 3.

[31] D. Derome, A. Rafsanjani, A. Patera, R. Guyer, J. Carmeliet, Philos. Mag. 92, 3680 (2012).

[32] J. Zaihan, C.A.S. Hill, S. Curling, in: International Research Group on Wood Protection, 40th Annual Meeting, Beijing (China) 2009, conference paper.

[33] J.E. Reeb, Drying Wood, FOR-55, Cooperative Extension Service, University of Kentucky, Lexington 1997.

[34] Bund Deutscher Klavierbauer e.V., Instructions for Avoiding Damage to Pianos by Climatic Influences (in German, access on 19th November 2017).

[35] Bundesverband Klavier e.V., Climate (in German, access on 19th November 2017).

[36] A. Rasa, in: Proc. 43rd Int. Congress and Exposition on Noise Control Engineering - Improving the World through Noise Control, Eds. J. Davy, T. McMinn, N. Broner, C. Don, L. Dowsett, M. Burgess, Internoise 2014, Melbourne (Australia) 2014, p. 4278.

[37] K.P. Menard, Dynamic Mechanical Analysis, A Practical Introduction, CRC Press, Boca Raton, Florida 1999.

[38] Netzsch Gabo Instruments GmbH (access on 29th December 2016).

[39] F. Krüger, E. Rohloff, Z. Phys. 110, 58 (1938).

[40] H. Sakai, A. Minamisawa, K. Takagi, Ultrasonics 28, 382 (1990).

[41] W.T. Simpson, in: Wood Handbook - Wood as an Engineering Material, United States Department of Agriculture, Forest Service, Forest Products Laboratory, General Technical Report FPL-GTR-113, Madison (WI) 1999, Ch. 12.

[42] W.N.A.W. Nadhari, R. Hashim, M. Danish, O. Sulaiman, S. Hiziroglu, Drying Technol. 32, 361 (2014).
[43] A. Vega-Gálvez, E. Uribe, M. Perez, G. TabiloMunizaga, J. Vergara, P. Garcia-Segovia, E. Lara, K. Di Scala, LWT Food Sci. Technol. 44, 384 (2011).

[44] G.E. Page, M.Sc. Thesis, Purdue University, West Lafayette (IN) 1949.

[45] H.Z. Hosseinabadi, K. Doosthoseini, M. Layeghi, Drvna Ind. 63, 169 (2012).

[46] A. Yağcioğlu, V. Demį,, T. Günhan, T. Mak. Bil. Derg. 3, 249 (2007).

[47] J. Wu, K.M. Berland, Biophys. J. 95, 2049 (2008).

[48] Z. He, Y. Zhang, S. Qiu, Z. Zhao, S. Yi, Wood Res. 61, 341 (2016).

[49] S. Avramidis, J.F. Siau, Wood Sci. Technol. 21, 249 (1987).

[50] A.J. Stamm, Forest Prod. J. 9, 27 (1959).

[51] J.F. Siau, Transport Processes in Wood, Springer, Berlin 1984.

[52] T. Gereke, Ph.D. Thesis (Diss. ETH No. 18427), Department of Civil, Environmental and Geomatic Engineering, Institute for Building Materials — Wood Physics, ETH Zurich 2009.

[53] W. Olek, J. Weres, Transp. Porous Med. 66, 135 (2007).

[54] Z. Perkowski, J. Świrska-Perkowska, M. Gajda, J. Bldg. Phys. 41, 1 (2016).

[55] H.D. Erickson, Mechanisms of Moisture Movement in Woods, presented at the 6th Annual Meeting of the Western Dry Kiln Clubs, Eureka (CA) 1954.

[56] F.F.P. Kollmann, Technology of Wood and Wood Materials, Springer, Berlin 1951 (in German).

[57] A.J. Stamm, Passage of Liquids, Vapors and Dissolved Materials through Softwoods U.S. Dept. Agric. Tech. Bull. 929, Washington D.C. 1946 , p. 48

[58] D.M. Burch, W.C. Thomas, A.H. Fanney, ASHRAE Trans. 98, 486 (1992).

[59] Q. Wu, O. Suchsland, Wood Fiber Sci. 28, 227 (1996).

[60] S. Ganev, A. Cloutier, R. Beauregard, G. Gendron, Wood Fiber Sci. 35, 68 (2003).

[61] J.F. Siau, Wood: Influence of Moisture on Physical Properties, Department of Wood Science and Forest Products, Virginia Polytechnic Institute and State University, Blacksburg 1995.

[62] A.L. Kimball, D.E. Lovell, Phys. Rev. 30, 948 (1927).

[63] R. Schmidt, Ing. Arch. 5, 352 (1934).

[64] E. Rohloff, Z. Phys. 117, 64 (1941).

[65] S. Amada, R.S. Lakes, J. Mater. Sci. 32, 2693 (1997).

[66] S. Amada, T. Munekata, Y. Nagase, Y. Ichikawa, A. Kirigai, Y. Zhifei, J. Compos. Mater. 30, 800 (1996).

[67] P. Mania, E. Fabisiak, E. Skrodzka, Arch. Acoust. 42 , 23 (2017).

[68] D. Ouis, Wood Sci. Technol. 36, 335 (2002).

[69] J. Göken, W. Riehemann, Mater. Sci. Eng. A 324, 134 (2002).

[70] A.S. Nowick, B.S. Berry, Anelastic Relaxation in Crystalline Solids, Academic Press, New York 1972.

[71] A. Granato, K. Lücke, J. Appl. Phys. 27, 789 (1956). 
[72] Z. Trojanová, P. Lukáč, H. Ferkel, W. Riehemann, Mater. Sci. Eng. A 370, 154 (2004).

[73] D. Fengel, Wood Sci. Technol. 25, 153 (1991).

[74] T. Noguchi, E. Obataya, K. Ando, J. Cult. Herit. 13S, S21 (2012).

[75] M. Tomassetti, L. Campanella, R. Tomellini, Thermochim. Acta 170, 51 (1990).

[76] K. Ahmet, G. Dai, R. Tomlin, P. Kaczmar, S. Riddiough, Forest Prod. J. 50, 64 (2000).
[77] H. Becker, D. Noack, Wood Sci. Technol.

$\mathbf{2}, 213$ (1968).

[78] T. Sadoh, Wood Sci. Technol. 15, 57 (1981).

[79] A.-M. Olsson, L. Salmén, Nord. Pulp. Pap. Res. J. 12, 140 (1997).

[80] A.P. Schniewind, Wood Sci. Technol. 2, 188 (1968). 